\title{
Simultaneous Description of Activity Coefficients and Solubility with eCPA
}

\author{
Schlaikjer, Anders; Thomsen, Kaj; Kontogeorgis, Georgios
}

Published in:

Industrial and Engineering Chemistry Research

Link to article, DOI:

10.1021/acs.iecr.6b03333

Publication date:

2017

Document Version

Peer reviewed version

Link back to DTU Orbit

Citation (APA):

Schlaikjer, A., Thomsen, K., \& Kontogeorgis, G. (2017). Simultaneous Description of Activity Coefficients and Solubility with eCPA. Industrial and Engineering Chemistry Research, 56(4), 1074-1089.

https://doi.org/10.1021/acs.iecr.6b03333

\section{General rights}

Copyright and moral rights for the publications made accessible in the public portal are retained by the authors and/or other copyright owners and it is a condition of accessing publications that users recognise and abide by the legal requirements associated with these rights.

- Users may download and print one copy of any publication from the public portal for the purpose of private study or research.

- You may not further distribute the material or use it for any profit-making activity or commercial gain

- You may freely distribute the URL identifying the publication in the public portal

If you believe that this document breaches copyright please contact us providing details, and we will remove access to the work immediately and investigate your claim. 


\title{
Simultaneous Description of Activity Coefficients and Solubility with eCPA
}

\section{Anders Schlaikjer, Kaj Thomsen and Georgios M. Kontogeorgis*}

Department of Chemical and Biochemical Engineering, Center for Energy Resources Engineering (CERE), Technical University of Denmark, DK-2800 Lyngby, Denmark

* Corresponding author, Tel.: +45 4525 2859, fax: +45 45882258, E-mail: gk@kt.dtu.dk

\begin{abstract}
In the many developments of electrolyte equations of state presented over the past decades several different properties have been in focus. A property that has not been widely used as a fitting property is salt solubility. This work presents a new parameterization of the eCPA equation of State with salt specific parameters. The focus is on accurate description of the salt solubility, and low deviation correlations are obtained for all salts investigated. The inclusion of the solubility data in the parameterization has, compared to parameters only parameterized to osmotic coefficients and activity coefficients, not significantly affected the deviations of the osmotic coefficients and activity coefficients. The average deviations of the activity coefficient does increase slightly and it was found that the increase in deviations was almost entirely due to reduced accuracy at high temperature and high molality. The model is, furthermore, compared to the activity coefficient model, Extended UNIQUAC. It is shown that the eCPA provides more accurate solubility description at higher temperatures than Extended UNIQUAC, but also that Extended UNIQUAC is slightly better at describing the activity coefficients. Overall the two models perform similarly.
\end{abstract}

Keywords: Equation of State; Electrolytes; Salt Solubility; Parameterization 


\section{Introduction}

Electrolytes have a significant effect in many industrial processes. In the oil and gas industry salts can, for instance, increase the inhibitory effect of methanol, ethanol and glycols on the formation of gas hydrates, and have an effect on the gas solubility in water-hydrocarbon mixtures ${ }^{1}$. Salts may enhance corrosion of pipelines and also precipitation of salts (scaling) may occur, due to the change in temperature, pressure and composition from reservoir to surface ${ }^{1,2}$. In the chemical industries, salts may induce liquid-liquid separation for some, otherwise miscible, liquids. Water-acetone is such a system which is miscible under normal conditions, but when adding specific salts a phase separation occurs $^{3-5}$. Accurate prediction of thermodynamic properties is important in the design and operation of processes, especially for complex mixtures. For many complex mixtures there are typically few or no experimental data, and therefore it is needed to use reliable thermodynamic models ${ }^{6}$.

Electrolyte systems are typically modeled with activity coefficient models such as the e-NRTL ${ }^{7}$, and Extended UNIQUAC ${ }^{8}$, however such models contain many adjustable parameters and may have difficulty in handling high pressures. Equations of State (EoS) represent an alternative and several EoSs for electrolytes have been developed over the past twenty years. However, no implementation has been developed to a stage where it can be seen as a reliable substitution to the successful activity coefficient models, many of which are available in commercial simulators ${ }^{6}$.

In the many developments of electrolyte EoSs, several different properties have been in focus. Both Galindo et al. ${ }^{9}$ and Cameretti et al. ${ }^{10}$ parameterized their models with density and vapor pressure of aqueous salt solutions in their original model presentation article, however, the same research groups 
have later reparametrized their models also including osmotic coefficients and activity coefficients in the parameter estimation ${ }^{11-13}$. Estimating parameters to activity coefficient or osmotic coefficients seems to be the most popular method in most recent works, with or without additionally using aqueous salt solution densities ${ }^{14-16}$. In the article by Maribo-Mogensen et al. ${ }^{17}$, a new electrolyte CPA (CubicPlus-Association) EoS was presented, and for this model the parameterization was based on activity coefficients and osmotic coefficients.

A property that has not been investigated in many electrolyte equations of state studies is salt solubility or Solid-Liquid-Equilibrium. Salt solubility can be complex, as for many salts the precipitating solid could be a hydrated form of the salts, and the hydrate number can change with temperature and composition. An additional problem is that standard state properties are needed for the solids, but such properties are often not readily available for all hydrated versions of a salt.

Only a single study has, to the author's knowledge, utilized solubility as a property for parameter estimation. Lin et al. used solubilities of salts in ternary aqueous systems along with apparent molar volumes, activity coefficients and osmotic coefficients at $298.15 \mathrm{~K}$ for parameter estimation ${ }^{18}$. In addition to this paper, only a handful of studies, where salt solubilities in two salts aqueous solutions at $298.15 \mathrm{~K}$ of a few selected systems are predicted, have been identified ${ }^{19-22}$. Studies investigating single salt solubilities in aqueous solutions at a wide range of temperatures, or mixed salt solubility at other temperatures that $298.15 \mathrm{~K}$, have not been identified in literature. The investigation of salt solubility with equations of state is thus limited to a few, relatively simple two salts systems, only at 298.15 K, and thus no investigations of the models capability with regards to solubility over a wider temperature range have been performed. 
In this work the goal is to parameterize the eCPA EoS of Maribo-Mogensen et al. ${ }^{17}$, including solubility data in the parameter estimation for obtaining as accurate solubility correlations as possible. At the same time it is sought to evaluate the effect of this parameter estimation method on the osmotic and activity coefficients, to which the model is also estimated. We also evaluate this new version of eCPA against the performance of the original model with the parameters of Maribo-Mogensen et al. Finally eCPA is compared against the Extended UNIQUAC model in order to compare its performance to a welldocumented and successful activity coefficient model. 


\section{The eCPA equation of State}

\subsection{The Model}

The model used in this work is the eCPA EoS proposed by Maribo-Mogensen et al. ${ }^{17}$. This EoS extends the CPA EoS, as proposed by Kontogeorgis et al. ${ }^{23}$, to account for electrostatic interactions and ion solvation through the use of the Debye-Hückel ${ }^{24}$ and Born ${ }^{25}$ models. In terms of the residual Helmholtz energy all the contributions are additive as shown in equation (1):

$$
A^{r}=A^{S R K}+A^{a s s o c}+\left(A^{D H}+A^{B o r n}\right)
$$

The full model is based on the cubic Soave-Redlich-Kwong EoS ${ }^{26}$, which, in terms of the residual Helmholtz energy, is calculated from equation (2):

$$
\frac{A^{S R K}}{n_{T} R T}=-\ln \left(1-\frac{b}{v}\right)-\frac{a(T)}{b R T} \ln \left(1+\frac{b}{v}\right)
$$

Where $n_{T}$ is the total number of moles, $\mathrm{T}$ is the temperature, $\mathrm{R}$ is the gas constant, and $v$ is the molar volume. There are two model parameters, the co-volume parameter, $b$, and the temperature dependent energy parameter, $a(T)$, given by equation (3):

$$
a(T)=a_{0}\left(1+c_{1}\left(1-\sqrt{T_{r}}\right)\right)^{2}
$$

Here $T_{r}$ is the reduced temperature defined as: $T_{r}=T / T_{c}$, where $T_{c}$ is the critical temperature. $a_{0}$ and $c_{1}$ are adjustable parameters. 
The residual Helmholtz energy for association is based on the formulation from SAFT ${ }^{27}$ of Wertheim's association theory ${ }^{28-31}$, and can be found from the solution of the constrained optimization problem given in equation (4) ${ }^{32,33}$ :

$$
\begin{gathered}
\frac{A^{a s s o c}}{R T}=\sum_{i} n_{i} \sum_{A \in i}\left(\ln X_{A_{i}}-\frac{1}{2} X_{A_{i}}+\frac{1}{2}\right) \\
\frac{1}{X_{A_{i}}}=1+\sum_{j} \rho_{j} \sum_{B \in j} X_{B_{j}} \Delta_{A_{i} B_{j}}
\end{gathered}
$$

In equation(4), $X_{A_{i}}$ is the fraction of site $A$ on component $i$ that is not bonded to any other site, $\rho_{i}$ is the density of component $i$, and $\Delta_{A_{i} B_{j}}$ is the association strength, which is calculated from equation (5):

$$
\Delta_{A_{i} B_{j}}=g(\rho)\left[\exp \left(\frac{\varepsilon_{A_{i} B_{j}}}{k_{B} T}\right)-1\right] b_{i j} \beta_{A_{i} B_{j}}
$$

In equation (5), the two association parameters are the association volume, $\beta_{A_{i} B_{j}}$, and the association energy, $\varepsilon_{A_{i} B_{j}}$, while $b_{i j}$ is given as: $b_{i j}=\left(b_{i}+b_{j}\right) / 2 . g(\rho)$ is the radial distribution function given by: $g(\rho)=(1-1.9 \eta)^{-1}$, where $\eta$ is the packing fraction given by $b / 4 v$. This is a simplified radial distribution function ${ }^{34}$ compared to the one used in the originally proposed CPA.

The ion-ion interaction contribution is calculated from the Debye-Hückel theory ${ }^{24}$, which in terms of residual Helmholtz energy is given in equation (6):

$$
A^{D H}=\frac{k_{B} T V}{4 \pi N_{A} \sum_{i} n_{i} z_{i}^{2}} \sum_{i} n_{i} z_{i}^{2} \chi_{\mathrm{i}}
$$


In equation (6), $T$ is temperature, $V$ is total volume, $z_{i}$ is the charge of component $i, k_{B}$ is the Boltzmann constant, and $N_{A}$ is the Avogadro number. The function $\chi_{i}$ is given by equation (7):

$$
\chi_{i}=\frac{1}{d_{i}^{3}}\left[\ln \left(1+\kappa d_{i}\right)-\kappa d_{i}+\frac{1}{2}\left(\kappa d_{i}\right)^{2}\right]
$$

In equation (7), $\kappa$ is the inverse Debye screening length, while $d_{i}$ is the hard-sphere diameter of the ion, $i$. The inverse Debye length can be calculated from equation (8):

$$
\kappa^{2}=\frac{e^{2}}{k_{B} T} \frac{1}{\varepsilon_{r} \varepsilon_{0}} \sum_{i} \rho_{i} Z_{i}^{2}
$$

Here, in equation (8), e is the elementary charge, $\varepsilon_{r}$ is the dielectric constant, $\varepsilon_{0}$ is the dielectric permittivity of vacuum, and $Z_{i}$ is the ionic valence of component $i$.

The final contribution to the residual Helmholtz energy is the Born ${ }^{25}$ model which is given in equation (9):

$$
A^{B o r n}=\frac{N_{A} e^{2}}{8 \pi \varepsilon_{0}} \sum_{i} \frac{n_{i} z_{i}^{2}}{R_{B o r n, i}}\left(\frac{1}{\varepsilon_{r}}-1\right)
$$

In equation (9), $R_{B o r n, i}$ is the radius of the Born cavity, which is caused by the transfer from vacuum to fluid phase. 
When handling mixtures, mixing and combining rules are needed. While CPA typically employs a quadratic mixing rule for the energy parameter, the electrolyte CPA uses the Huron-Vidal infinite pressure mixing rule as shown in equation (10) and the linear mixing rule for the co-volume parameter as shown in equation (11):

$$
\begin{gathered}
\frac{a}{b}=\sum_{i} x_{i} \frac{a_{i}}{b_{i}}-\frac{g^{E, \infty}}{\ln 2} \\
b=\sum_{i} x_{i} b_{i}
\end{gathered}
$$

The excess Gibbs energy of the infinite pressure Huron-Vidal mixing rule is calculated using the modified Huron-Vidal/NRTL equation shown in equation (12):

$$
\frac{g^{E, \infty}}{R T}=\sum_{i} x_{i} \frac{\sum_{j} x_{j} b_{j} \exp \left(-\alpha_{j i} \frac{\Delta U_{j i}}{R T}\right) \frac{\Delta U_{j i}}{R T}}{\sum_{j} x_{j} b_{j} \exp \left(-\alpha_{j i} \frac{\Delta U_{j i}}{R T}\right)}
$$

In this equation, $\alpha_{j i}$, is the NRTL non-randomness parameter and $\Delta U_{j i}$ is the change in interaction energy between like and unlike interactions, i.e. $\Delta U_{j i}=U_{i j}-U_{j j}$. As the already existing CPA parameter should be used for non-electrolytes it is important to note that this mixing rule can reduce to the traditional quadratic mixing rule by setting $\alpha_{i j}=\alpha_{j i}=0, \frac{\Delta U_{j i}}{\ln 2}=\left(\frac{2 a_{i}}{b_{i}}-\frac{a_{j i}}{b_{j}}\right)$, and $a_{i j}=$ 
$\sqrt{a_{i} a_{j}}\left(1-k_{i j}\right)$. In this work, no systems with cross association are presented and thus there is no need for combining rules for the association parameter.

For this model, the Huron-Vidal/NRTL mixing rule is simplified by setting the non-randomness parameter to zero by default, which results in the following expression shown in equation (13):

$$
\frac{g_{\text {ions }}^{E, \infty}}{R T}=\frac{1}{b} \sum_{i} \sum_{j} x_{i} x_{j} b_{j} \frac{\Delta U_{j i}}{R T}
$$

While the entire framework of the model is ion specific, it is due to the simplification of the Huron-Vidal mixing rule possible to use salt specific interaction energy parameters between a salt and solvent, as salt specific parameters are related to ion specific ones through equation (14):

$$
\frac{\Delta U_{s w}}{R T}=\sum_{j \in s}^{\text {ions }} \frac{v_{j}\left(b_{j}+b_{w}\right)}{v_{s} b_{i}+b_{s}} \frac{\Delta U_{j w}}{R T}
$$

Here $v_{j}$ is the stoichiometric number of ion $j$ in salt, $s$, here with water $(\mathrm{w})$ as a solvent. $v_{s}$ is the total stoichiometric number of dissociated molecules in salt $s$ and $b_{s}$ is the co-volume parameter of the salt calculated from the ion co-volumes by: $b_{s}=\sum_{j \in s} v_{j} b_{j}$. Employing salt specific parameters, however, require an additional thermodynamic condition such as equating the contribution from the cation and anion, $\Delta U_{c w}=\Delta U_{a w}$, which is what is done for pure salts. In the case where the model is applied to mixed salt systems there is a need for a common ion, as it is then possible through equation (14) to 
calculate the input for each ion by setting the value of the common ion equal to zero. Thus in a mixture of for instance, $\mathrm{Na}^{+}, \mathrm{K}^{+}$and $\mathrm{Cl}^{-}$, the cation-water interaction energy in equation (14) is set to zero, while the salt-water interaction energy is the known parameter of both $\mathrm{NaCl}$ or $\mathrm{KCl}$. This will produce two equations, one for $\mathrm{NaCl}$ and one for $\mathrm{KCl}$, from which the two anion-water interaction contributions can be calculated.

Finally it has been found that a temperature dependency of the interaction energy parameter is needed 17. A quadratic temperature dependency has been developed for the salt-water interaction parameters as shown in equation $(15)^{17}$ :

$$
\frac{\Delta U_{w s}}{R}=\frac{\Delta U_{w s}^{r e f}}{R}+\alpha_{w s}\left[\left(1-\frac{T}{T_{\alpha, w s}}\right)^{2}-\left(1-\frac{T_{r e f}}{T_{\alpha, w s}}\right)^{2}\right]
$$

In equation (15), $\Delta U_{w s}^{r e f}$ is the reference interaction energy parameter at a reference temperature, $T_{\text {ref }}$. This temperature is typically set to $298.15 \mathrm{~K}$ as this is a temperature where sufficient data are often available. $\alpha_{w s}$ and $T_{\alpha, w s}$ are parameters of the temperature dependency yielding a total of three adjustable parameters, within the mixing rule, for every salt-water binary.

\subsection{Solid-liquid equilibrium}

In order to describe any equilibrium, an equilibrium equation is needed, but unlike the vapor-liquid equilibrium, where the EoS can describe both phases, in the solid-liquid equilibrium the EoS cannot describe the solid phase which rely on standard state properties. The equilibrium equation of the Solid liquid Equilibrium (SLE) used here is shown in equation (16): 


$$
\ln K_{s}=R T \sum_{i} v_{i, s} \ln a_{i}
$$

Here $a_{i}$ is the component activities of all components in the fluid phase and $K_{S}$ is calculated from equation (17):

$$
\begin{aligned}
R \ln K_{S}=-\frac{\Delta_{S} G_{T_{0}, P_{0}}^{0}}{T_{0}}+\Delta_{S} H_{T_{0}, P_{0}}^{0}\left(\frac{1}{T_{0}}-\frac{1}{T}\right)+\Delta a\left(\ln \frac{T}{T_{0}}+\frac{T_{0}}{T}-1\right) \\
+0.5 \Delta b\left(\frac{\left(T-T_{0}\right)^{2}}{T}\right)+\frac{\Delta c}{T_{\Theta}}\left(\frac{T-T_{\Theta}}{T} \ln \frac{T-T_{\Theta}}{T_{0}-T_{\Theta}}+\ln \frac{T_{0}}{T}\right)
\end{aligned}
$$

In equation (17), $\Delta_{S} G_{T_{0}, P_{o}}^{0}$ and $\Delta_{S} H_{T_{0}, P_{o}}^{0}$ are the difference in Gibbs free energy of formation and the enthalpy of formation between the solid and liquid phases. $\Delta a, \Delta b$ and $\Delta c$ are the differences in the three parameters of the standard state heat capacity correlation shown in equation (18). $T_{\Theta}$ is given as $200 \mathrm{~K}$ and $T_{0}$ is the temperature of the standard state typically $298.15 \mathrm{~K}$ :

$$
C_{p, i}^{0}=a_{i}+b_{i} T+\frac{c_{i}}{T-T_{\Theta}}
$$

This correlation is identical to the one used in modelling with Extended UNIQUAC ${ }^{35}$ and the heat capacity correlations of the ions are adapted from this. The solid salt heat capacities are, however, assumed temperature independent, thus only contributing to the $\Delta a$ coefficient in equation (17). The Gibbs energy and enthalpy of formation, as well as the heat capacity coefficients of the ions can be found in Table 1. 


\subsection{Parameter estimation}

This eCPA EoS potentially has many free parameters; however, the number of adjustable parameters is limited by linking individual parameters to specific literature data, and by employing assumptions. The parameters of the electrolyte part of the model, the Debye-Hückel and Born terms, include a size parameter in each term as well as the static permittivity, or dielectric constant, also in both terms. The static permittivity has previously been found to be a key parameter for the performance of electrostatic interaction models, and depends on temperature, volume and composition ${ }^{36}$. The model of MariboMogensen et al. ${ }^{37}$ is, thus, used to obtain the static permittivity, $\varepsilon_{r}$, as this model has shown accurate predictions for complex hydrogen bonding fluids ${ }^{37}$ :

$$
\frac{\left(2 \varepsilon_{r}+\varepsilon_{\infty}\right)\left(\varepsilon_{r}-\varepsilon_{\infty}\right)}{\varepsilon_{r}}=\left(\frac{\varepsilon_{\infty}+2}{3}\right)^{2} \frac{N_{A}}{\varepsilon_{0} k_{B} T \nu} \sum_{i} x_{i} g_{i} \mu_{i, 0}^{2}
$$

In this $\varepsilon_{\infty}$ is the infinite frequency permittivity, $\mu_{i, 0}$ is the vacuum dipole moment, and $g_{i}$ is the Kirkwood g-factor as obtained by Maribo-Mogensen ${ }^{37}$. As already mentioned, the size parameter in the Debye-Hückel (equation (7)), is set as the hard sphere diameter of the ions. These hard-sphere diameters are obtained from Marcus and are shown in Table $1^{38}$.

The size parameter in the Born term is the radius of the Born cavity, denoted, $R_{B o r n, i}$ in equation (9). As discussed by Maribo-Mogensen et al. ${ }^{17}$, different approaches for estimating this parameter can be found in literature. Some have used the same diameter as used in the Debye-Hückel or MSA term ${ }^{14,22,39}$, but others have used an adjustable diameter, typically increased due to the effect of hydration 
compared to the hard-sphere diameter ${ }^{16,18,40-46}$. Maribo-Mogensen et al. ${ }^{17}$ estimated the Born radius to match the hydration enthalpy at $298.15 \mathrm{~K}$ calculated with eCPA, as the Born term has by far the most significant contribution to this property. The hydration enthalpy is calculated from the aqueous standard state enthalpy of formation for each fully dissociated salt $\left(\Delta_{f} H(s, a q)\right)$, and the ideal gas formation enthalpy of each ion $\left(\Delta_{f} H(c / a, g)\right)$, through equation (20):

$$
\Delta_{h y d} H(s)=\Delta_{f} H(s, a q)-\sum_{i=c, a} \Delta_{\mathrm{f}} H(i, g)
$$

Here $v$ is the stoichiometric coefficient of the ions with in the salt, and $c$ and $a$, designates cation and anion respectively. Maribo-Mogensen et al. matched these values to eCPA calculations, as the hydration enthalpy for each ion can be calculated trough equation (21):

$$
\Delta_{h y d} H(i)=\lim _{n_{i} \rightarrow 0}\left[H_{i}^{l i g}-H_{i}^{i g}\right]=\lim _{n_{i} \rightarrow 0}\left[R T^{2}\left(\frac{\partial \ln \varphi_{i}^{l}}{\partial T}\right)_{P}\right]
$$

The total hydration enthalpy of a salt can then be calculated from equation (22):

$$
\Delta_{h y d} H(s)=v_{c} \Delta_{h y d} H(c)+v_{a} \Delta_{h y d} H(a)
$$

A similar procedure could be performed in this work, as this property will be slightly affected by other parameters. However, in this work it is chosen to use the values of the parameters found by MariboMogensen et al. ${ }^{17}$. This decision is based on the assumption that the contributions from the other terms of the EoS will be small and, thus, the change in the Born radius would be very small to adjust for this. The radius value of the relevant ions are comparable to those of Rashin and Honig ${ }^{47}$, which indicates that the values used here are reasonable. 
Table 1: Ionic-specific size parameters, $d_{i}$ is the hard-sphere diameter adopted from Marcus ${ }^{38}, b_{i}$ is the co-volume parameter (equation (23)), $\boldsymbol{R}_{\text {Born }}$ is the Born radius adopted from Maribo-Mogensen et al. ${ }^{17}$. $\Delta_{\text {form }} G, \Delta_{\text {form }} H$ and $C_{p}^{0}$ is the standard state properties used for the ions, where the coefficients of the heat capacity corresponds the equation (18). The Gibbs energy and enthalpy properties are adopted from Wagman et al. ${ }^{48}$.

\begin{tabular}{ccccccccc}
\hline & $\begin{array}{c}\boldsymbol{d}_{\boldsymbol{i}} \\
(\AA)\end{array}$ & $\begin{array}{c}\boldsymbol{b}_{\boldsymbol{i}} \\
\left(\mathrm{cm}^{3} / \mathrm{mol}\right)\end{array}$ & $\begin{array}{c}\boldsymbol{R}_{\boldsymbol{B o r n}} \\
(\AA)\end{array}$ & $\begin{array}{c}\boldsymbol{\Delta}_{\text {form }} \boldsymbol{G} \\
(\mathbf{k J} / \mathbf{m o l})\end{array}$ & $\begin{array}{c}\boldsymbol{\Delta}_{\text {form }} \boldsymbol{H} \\
(\mathbf{k J} / \mathbf{m o l})\end{array}$ & $\begin{array}{c}\boldsymbol{C}_{P}^{\mathbf{0}}(\boldsymbol{a}) \\
(\boldsymbol{J} / \mathbf{m o l} / \mathbf{K})\end{array}$ & $\begin{array}{c}\boldsymbol{C}_{\boldsymbol{P}}^{\mathbf{0}}(\boldsymbol{b}) \\
\left(\boldsymbol{J} / \mathbf{m o l} / \boldsymbol{K}^{\mathbf{2}}\right)\end{array}$ & $\begin{array}{c}\boldsymbol{C}_{\boldsymbol{P}}^{\mathbf{0}}(\boldsymbol{c}) \\
(\boldsymbol{J} / \mathbf{m o l})\end{array}$ \\
\hline $\mathbf{N a}^{+}$ & 2.08 & 11.35 & 1.319 & -261.9 & -240.1 & 600.6 & 1.101 & 23232 \\
$\mathbf{K}^{+}$ & 2.36 & 16.49 & 1.665 & -283.3 & -252.4 & 415.1 & 0.814 & 16316 \\
$\mathbf{M g}^{++}$ & 2.09 & 11.51 & 1.443 & -454.8 & -466.9 & -647.0 & 1.331 & 22717 \\
$\mathrm{Cl}^{-}$ & 3.19 & 40.83 & 1.828 & -131.2 & -167.2 & 400.4 & 1.131 & 18574 \\
$\mathrm{Br}^{-}$ & 3.37 & 48.40 & 2.059 & -104.0 & -121.6 & -177.8 & -0.063 & 6651 \\
$\mathbf{N O}_{3}^{-}$ & 3.16 & 39.80 & 2.050 & -111.3 & -207.4 & 2.3 & 0.121 & -9753 \\
$\mathbf{S O}_{4}^{--}$ & 3.82 & 70.03 & 2.415 & -744.5 & -909.3 & 643.3 & 1.760 & 37903 \\
\hline
\end{tabular}

The remaining pure component parameters are the ones of the classical CPA, and as the model does not take ion association into account there is no need for association parameters for the ions. The covolume parameter is calculated from the hard-sphere diameter obtained from Marcus using equation (23) and can be found in Table $1^{38}$ :

$$
b_{i}=\frac{2}{3} N_{A} \pi d_{i}^{3}
$$

Since ions cannot exist in a pure form, but only as part of a salt or dissolved in a solvent, binary data must be used for parameter regression. This suggests that the pure component energy parameter in the SRK part and the interaction energy of the Huron-Vidal/NRTL mixing rule should be estimated based on the same data. This could lead to inconsistencies in the parameters as two parameters are 
representing more or less the same. It is therefore chosen to set the energy parameter of the SRK part constant $\left(\mathrm{a}_{0}=0\right)$. Only the interaction energy between each ion and the solvent needs then to be fitted. In this work, similarly to Maribo-Mogensen et al. ${ }^{17}$ salt specific interaction parameters are used. This interaction energy parameter between solvent and salt is the only parameter of the model adjusted to experimental data. Including the temperature dependency shown in equation (15), however, the number of adjustable parameters increases to 3.

In the original parameterization by Maribo-Mogensen at el. ${ }^{17}$ the $T_{\alpha}$ parameter was not truly adjustable, but chosen constant for all salts with a specific anion, e.g. chloride salts have a $T_{\alpha}$ of $340 \mathrm{~K}$, and so on. In this work, however, this parameter is a free adjustable parameter, but it was restricted to be in a reasonable range of $250-400 \mathrm{~K}$.

The standard state properties for solids used in equation (17), are adopted from Wagman et al. ${ }^{48}$ for anhydrous salts. For most hydrated salts, standard state property data are however, not available in such databases. For the hydrated salts the Gibbs energy and enthalpy of formation were used as adjustable parameters, while the heat capacity was estimated from equation (24):

$$
C_{p, \text { salt } \cdot n \mathrm{H}_{2} \mathrm{O}}^{0}=C_{p, \text { salt }}^{0}+n \cdot 40\left(\frac{\mathrm{J}}{\mathrm{molK}}\right)
$$

In equation (24), $n$ is the hydration number, and 40 is an approximate value for the heat capacity of water in the solid state. This value is slightly lower than the standard state value of ice, however it is found that when in hydrates the effect is slightly lower than the ice value. As an initial value for the 
Gibbs energy and enthalpy of formation for the hydrated salts, values regressed with the Extended UNIQUAC model are used, and these initial guess values can be found in Table 6.

Table 2: CPA parameters for water ${ }^{34}$.

\begin{tabular}{lllllll}
\hline \multicolumn{1}{c}{$T_{\boldsymbol{c}}$} & $\boldsymbol{b}$ & $\Gamma=\frac{\boldsymbol{a}_{\mathbf{0}}}{\boldsymbol{R b}}$ & $\boldsymbol{c}_{\mathbf{1}}$ & $\boldsymbol{\beta}_{\boldsymbol{A}_{i} \boldsymbol{B}_{j}} \cdot \mathbf{1 0}^{\mathbf{3}}$ & $\frac{\varepsilon_{\boldsymbol{A}_{i} B_{j}}}{\boldsymbol{k}_{\boldsymbol{B}}}$ & Association Scheme \\
\hline (K) & $\frac{\boldsymbol{c m}^{\mathbf{3}}}{\mathbf{m o l}}$ & (K) & & & (K) & \\
\hline 657.13 & 14.52 & 1017.3 & 0.6736 & 69.2 & 2003.25 & $4 \mathrm{C}$ \\
\hline
\end{tabular}

In this work the model is parameterized with water as a solvent, using the already existing CPA parameters for water, shown in Table 2 . With these water parameters and the ion specific parameters for the ions presented above (Table 1), the 3 parameters of the interaction energy temperature dependency (equation (15)), and the adjustable standard state properties of solids, were regressed to osmotic and activity coefficients up to a molality matching the solubility limit, as well as solubility data. The osmotic coefficient and the activity coefficients are linked through the Gibbs-Duhem equation (equation (25)) and are essentially two measures of the same thing. Both are used in the regression as both types are available and to ensure data at as many temperatures as possible.

$$
\ln \gamma_{ \pm}^{m}=\Phi-1+\int_{0}^{m_{i}} \frac{\Phi-1}{m} d m
$$

The objective function for the regression is given as the additive sum, equation (26), of two residual functions shown in equations (27) and (28), where $w_{i}$ is a weight given to the datapoint, $i$ : 


$$
\begin{gathered}
R=R 1+R 2 \\
R 1=\sum_{i}\left(\frac{\gamma_{\text {exp }}^{ \pm}-\gamma_{\text {calc }}^{ \pm}}{\gamma_{\text {exp }}^{ \pm}}\right)^{2} w_{\gamma^{ \pm} i}+\sum_{i}\left(\frac{\phi_{\text {exp }}-\phi_{\text {calc }}}{\phi_{\text {exp }}}\right)^{2} w_{\phi i} \\
R 2=\sum_{i}\left(\ln K_{i}-\left(\sum_{j} v_{j, i} \ln \left(a_{j, i}^{*} m_{j, i}\right)+v_{w, i} \ln a_{w, i}\right)\right)^{2} w_{S L E}
\end{gathered}
$$

In this work the weight has primarily been used to ensure accurate description of the solubility of the salts, as well as putting more weight on higher molality and temperature due to fewer data points in these ranges. Adjusting the weights has been done individually for each salt in an iterative manner until satisfactory solubility representation has been observed. For all salts the weights are initially set to 1 altogether. This works well for a few salts, however for most salts it is unsatisfactory. In order to accurately capture the solubility over extensive temperatures, the solubility data are typically weighted up to 5 times higher than the osmotic coefficient and activity coefficient data. For some of the salts it was observed that getting low deviations in the solubility at high temperatures was an issue. This is mainly due to the large amount of low temperature data and the lower amount of high temperature data. To accommodate this, data over $350 \mathrm{~K}$ was weighted up to 10 times higher than low temperature solubility data, depending on the salt. It should be noted that equation (27) is very similar to the objective function used in the work by Maribo-Mogensen et al. ${ }^{17}$, and that the entire objective function is similar to the one used for Extended UNIQUAC ${ }^{35}$.The data used for the parameter regression are 
found from the DTU CERE electrolyte database ${ }^{49}$, and an overview of the data used in the parameter estimation is shown in Table 3.

The procedure for the parameter regression is not straightforward and is not identical for all salts. In all cases the Maribo-Mogensen et al. ${ }^{17}$ parameters were used as the initial estimate for the parameter optimization. For salts where the only precipitate, in the relevant temperature region, is the anhydrous salt, the procedure is, however, fairly straightforward. The standard state properties of the solid are here kept constant and thus only the interaction energy parameters of eCPA are estimated. This procedure is similar to the procedure used by Maribo-Mogensen et al. ${ }^{17}$, with the addition that solubility data are included in the parameter fitting. For salts which precipitate in hydrated form, the parameter estimation is more complex, as both eCPA parameters and solid standard state properties are estimated. The optimization routine for this type of salt system is not uniform and differs between the salts. For the salts that only form hydrates at low temperatures while at high temperatures precipitate in anhydrous form such as $\mathrm{NaCl}$, the parameter estimation is based on simultaneous optimization of the interaction energy parameters of eCPA and the standard state properties of the hydrated solids. For salts only precipitating hydrated, such as magnesium salts, several different intermediate steps must be employed to obtain suitable parameters. Intermediate optimization steps could include; only optimizing to one of the two residual functions (equations (27) and (28)), only optimizing the eCPA parameters with constant standard state properties and reversely only optimizing the standard state properties with constant eCPA parameters. A series of these intermediate steps are often necessary, and result in unique optimization routines depending on the salt. The parameter 
estimation is discussed in detail in the discussion, also offering insight into specific routines for each salt. 
Table 3: Experimental data used in the parameter regression. All data are from the DTU CERE electrolyte database ${ }^{49}$. The limit in molality is set at the solubility limit. $n_{d p}$ is the number of data points, @25 ${ }^{\circ} \mathrm{C}$ is the number of data points at $25^{\circ} \mathrm{C}, \mathrm{m}_{\max }$ is the maximum molality of the salt, $\mathrm{T}_{\min }$ and $T_{\max }$ is the maximum and minimum temperature respectively.

\begin{tabular}{|c|c|c|c|c|c|c|c|c|c|c|c|c|c|c|}
\hline & \multicolumn{5}{|c|}{$\Phi$} & \multicolumn{5}{|c|}{$\gamma^{ \pm}$} & \multicolumn{4}{|c|}{ Solubility } \\
\hline & $\mathrm{n}_{\mathrm{dp}}$ & $\begin{array}{l}\mathrm{n}_{\mathrm{dp}} \\
@ 25^{\circ} \mathrm{C}\end{array}$ & $\begin{array}{l}m_{\max } \\
\text { (molal) }\end{array}$ & $\begin{array}{l}T_{\min } \\
(K)\end{array}$ & $\begin{array}{l}T_{\max } \\
\text { (K) }\end{array}$ & $\mathrm{n}_{\mathrm{dp}}$ & $\begin{array}{l}\mathrm{n}_{\mathrm{dp}} \\
@ 25^{\circ} \mathrm{C}\end{array}$ & $\begin{array}{l}m_{\max } \\
\text { (molal) }\end{array}$ & $\begin{array}{l}T_{\min } \\
\text { (K) }\end{array}$ & $\begin{array}{l}T_{\max } \\
\text { (K) }\end{array}$ & $\mathrm{n}_{\mathrm{dp}}$ & $\begin{array}{l}m_{\max } \\
\text { (molal) }\end{array}$ & $\begin{array}{l}T_{\min } \\
(K)\end{array}$ & $\begin{array}{l}T_{\max } \\
\text { (K) }\end{array}$ \\
\hline $\mathrm{NaCl}$ & 988 & 229 & 7.97 & 273.15 & 473.15 & 727 & 53 & 6 & 273.15 & 523.15 & 571 & 7.97 & 253.15 & 473.15 \\
\hline $\mathrm{NaBr}$ & 210 & 118 & 11.59 & 272.66 & 374.15 & 212 & 68 & 9 & 273.15 & 523.15 & 106 & 14.28 & 245.85 & 453.15 \\
\hline $\mathrm{Na}_{2} \mathrm{SO}_{4}$ & 312 & 143 & 3.5 & 273.15 & 498.15 & 123 & 51 & 3.5 & 273.15 & 498.15 & 460 & 3.57 & 272.15 & 465.15 \\
\hline $\mathrm{NaNO}_{3}$ & 193 & 130 & 15.99 & 273.15 & 373.45 & 34 & 34 & 10.83 & 298.15 & 298.15 & 317 & 56.24 & 255.05 & 471.15 \\
\hline $\mathrm{KCl}$ & 630 & 169 & 8.07 & 273.15 & 598.15 & 535 & 93 & 6 & 273.15 & 598.15 & 552 & 10.93 & 262.05 & 473.15 \\
\hline $\mathrm{KBr}$ & 65 & 55 & 5.5 & 298.15 & 318.15 & 88 & 40 & 5 & 273.15 & 523.15 & 154 & 12.24 & 260.95 & 454.15 \\
\hline $\mathrm{K}_{2} \mathrm{SO}_{4}$ & 162 & 64 & 2.0 & 273.15 & 498.15 & 90 & 31 & 2.0 & 273.15 & 498.15 & 245 & 1.97 & 271.65 & 466.15 \\
\hline $\mathrm{KNO}_{3}$ & 203 & 133 & 15 & 274.15 & 348.15 & 24 & 24 & 3.5 & 298.15 & 298.15 & 270 & 80.03 & 270.31 & 473.15 \\
\hline $\mathrm{MgCl}_{2}$ & 309 & 169 & 6 & 298.15 & 473.15 & 98 & 56 & 5.92 & 273.15 & 523.15 & 321 & 14.09 & 239.55 & 473.15 \\
\hline $\mathrm{MgBr}_{2}$ & 63 & 48 & 5.83 & 273.15 & 323.15 & 62 & 62 & 5.61 & 298.15 & 298.2 & 56 & 9.26 & 240.02 & 445.55 \\
\hline $\mathrm{MgSO}_{4}$ & 156 & 84 & 5 & 273.15 & 448.15 & 36 & 9 & 3.5 & 273.15 & 383.15 & 184 & 5.02 & 269.15 & 468.15 \\
\hline $\mathrm{Mg}\left(\mathrm{NO}_{3}\right)_{2}$ & 197 & 151 & 5.73 & 273.15 & 323.15 & 78 & 13 & 0.51 & 273.15 & 318.15 & 188 & 37.04 & 242.35 & 459.15 \\
\hline
\end{tabular}

\section{Results}

The focus of this work was to investigate the ability of the model to describe mean ionic activity and osmotic coefficients as well as solubility using a single parameter set. For this investigation, a range of salt solutions with ions: $\mathrm{Na}^{+}, \mathrm{K}^{+}, \mathrm{Mg}^{2+}, \mathrm{Cl}^{-}, \mathrm{Br}^{-}, \mathrm{SO}_{4}{ }^{2-}$ and $\mathrm{NO}_{3}{ }^{-}$, were parameterized using the estimation procedure described previously. The interaction energy parameters of the 12 salts are listed in Table 4, while relative deviations for osmotic coefficients, mean ionic activity coefficients and solubility data 
from Table 3, are shown in Table 5. The deviations are presented as Relative Average Deviations (RAD) defined in equation (29):

$$
R A D=\frac{1}{N} \sum_{i}^{N}\left|\frac{x_{i}^{\text {exp }}-x_{i}^{\text {calc }}}{x_{i}^{\text {exp }}}\right|
$$

Here $N$ is the number of data points, and $x$ represents any property. For solubility deviations the model is evaluated in terms of molality deviations at the given temperature. For comparison, the parameters of Maribo-Mogensen et al. ${ }^{17}$ are also presented in Table 4. The associated relative deviations are presented in Table 5, where deviations using Maribo-Mogensen et al. parameters ${ }^{17}$ and Extended UNIQUAC $^{35}$ are also shown. Extended UNIQUAC deviations are only calculated for data of $383.15 \mathrm{~K}$ or below, as this is the temperature limit of the model, and for comparison, deviations for the same temperature interval can be found in brackets for the two eCPA parameterizations. The deviations for the activity and osmotic coefficients are found to increase slightly using the parameters of this work compared to eCPA with the parameters of Maribo-Mogensen et al. The average relative average deviation for the osmotic coefficient increase from $4.0 \%$ to $4.6 \%$, and from $6.8 \%$ to $7.9 \%$ for the mean ionic activity coefficient (Table 5). For most of the salts investigated the change in relative average deviation is small, however a few of the salts stand out. For $\mathrm{NaBr}$ and $\mathrm{KBr}$ the deviations for osmotic coefficients are small and similar to that of Maribo-Mogensen et al. The deviation for mean ionic activity coefficients is, however, high $(\approx 10 \%)$ and while the deviations with the Maribo-Mogensen et al. parameters are also in the high end compared to the other salts, there is also a significant increase. In Table 6 the standard state properties of solids are listed for all relevant solid salts, such that both the 
newly estimated values and the values obtained from the Extended UNIQUAC database are shown. The solubility calculations using the parameters of Maribo-Mogensen et al. ${ }^{17}$ employ the standard state properties of solids of the Extended UNIQUAC database. The parameterization approach in this work, where solubility is included in the parameter estimation, greatly reduces the deviations in the solubility description compared to Maribo-Mogensen et al. ${ }^{17}$ parameters. More specifically, for the salts investigated, the solubility deviations goes from $10.3 \%$ (excluding three salt solutions where the calculation failed with the original set of parameters $\left(\mathrm{MgCl}_{2}, \mathrm{MgBr}_{2}\right.$ and $\left.\left.\mathrm{Mg}\left(\mathrm{NO}_{3}\right)_{2}\right)\right)$, to just 3.0\% including the three problematic salts. For all the salts investigated, the solubility is correlated accurately in the whole temperature range of the data, roughly $273.15 \mathrm{~K}$ to $473.15 \mathrm{~K}$, as exemplified in Figure 1 where the solubility of four salts is presented. The results are also compared to eCPA with MariboMogensen et al. ${ }^{17}$ parameters, and to Extended UNIQUAC. The $\mathrm{NaCl}$ solubility plot is representative for the $\mathrm{Na}^{+}$and $\mathrm{K}^{+}$salts investigated in terms of performance between the models and parameterizations. In all such cases the Maribo-Mogensen parameters generally capture the freezing point depression as well as the solubility at low temperatures, but deviate at higher temperatures. This is very clear for the $\mathrm{NO}_{3}{ }^{-}$salts, which generally have very high solubility, where the deviations are significant at higher temperatures. The Extended UNIQUAC model generally captures the freezing point depression and solubility up to the temperature limitation of the model, $383.15 \mathrm{~K}$, however, the trend at the high temperatures suggests that extrapolation to higher temperatures would yield higher deviations for some of the salts. For the $\mathrm{Mg}^{2+}$ salts, only the $\mathrm{MgSO}_{4}$ solubility could be calculated, still inaccurately, with the Maribo-Mogensen parameters. The solubility of other salts investigated were modelled 
somewhat accurately at low temperature, but significant deviations at low temperature were observed for $\mathrm{MgSO}_{4}$. For the three other $\mathrm{Mg}^{2+}$ salts the modelling yielded no meaningful results. 
Table 4: Parameters of equation (15) estimated using the procedure described in this work. The parameters of Maribo-Mogensen et al. ${ }^{17}$ are also shown for comparison purposes.

\begin{tabular}{|c|c|c|c|c|c|c|}
\hline \multirow[t]{2}{*}{ Salt } & \multicolumn{3}{|l|}{ This work } & \multicolumn{3}{|c|}{ Maribo-Mogensen et al. ${ }^{17}$} \\
\hline & $\begin{array}{l}\Delta U_{r e f} / R \\
@ 25^{\circ} \mathrm{C}(\mathrm{K})\end{array}$ & ${ }_{(\mathrm{K})}{ }^{\alpha}$ & $\begin{array}{l}T_{\alpha} \\
(\mathrm{K})\end{array}$ & $\begin{array}{l}\Delta U_{r e f} / R \\
@ 25^{\circ} \mathrm{C}(\mathrm{K})\end{array}$ & ${ }_{(\mathrm{K})}{ }^{\alpha}$ & $\begin{array}{r}T_{\alpha} \\
(\mathrm{K})\end{array}$ \\
\hline $\mathrm{NaCl}$ & -225.15 & 1539.1 & 333.06 & -223.52 & 1572.3 & 340 \\
\hline $\mathrm{NaBr}$ & -291.33 & 1891.0 & 339.03 & -280.339 & 1321.5 & 350 \\
\hline $\mathrm{Na}_{2} \mathrm{SO}_{4}$ & 129.09 & 1618.0 & 304.28 & 123.845 & 1163.16 & 300 \\
\hline $\mathrm{NaNO}_{3}$ & -18.79 & 2954.9 & 301.40 & -40.88 & 846 & 340 \\
\hline $\mathrm{KCl}$ & -137.36 & 1483.6 & 324.15 & -129.99 & 1361.45 & 340 \\
\hline $\mathrm{KBr}$ & -151.56 & 1515.5 & 332.39 & -162.827 & 1047.02 & 350 \\
\hline $\mathrm{K}_{2} \mathrm{SO}_{4}$ & 87.15 & 1584.6 & 324.82 & 77.38 & 891.52 & 300 \\
\hline $\mathrm{KNO}_{3}$ & 38.27 & 4549.5 & 304.6 & 48.41 & 445.83 & 340 \\
\hline $\mathrm{MgCl}_{2}$ & -521.75 & 1063.2 & 306.91 & -459.59 & 2439.49 & 340 \\
\hline $\mathrm{MgBr}_{2}$ & -515.73 & 767.14 & 349.91 & -526.244 & 1801.5 & 350 \\
\hline $\mathrm{MgSO}_{4}$ & 120.70 & 2647.5 & 297.86 & 124.33 & 2618.72 & 300 \\
\hline $\mathrm{Mg}\left(\mathrm{NO}_{3}\right)_{2}$ & -506.37 & 1388.4 & 342.72 & -427.98 & 524.585 & 340 \\
\hline
\end{tabular}


Table 5: Deviations from the experimental data, in forms of RAD (equation (29)), used in the regression, along with the corresponding deviations using the parameters of Maribo-Mogensen et al. ${ }^{17}$, and comparison with Extended UNIQUAC ${ }^{35}$. Solubility deviations are molal deviations for each specified temperature. Temperature and molality range of data are shown in Table 3 for eCPA, while extended UNIQUAC is only applied to data up to $383.15 \mathrm{~K}$. For comparison eCPA deviations, for osmotic coefficient and mean ionic activity coefficient, up to 383.15K are shown in brackets.

\begin{tabular}{|c|c|c|c|c|c|c|c|c|c|}
\hline \multirow[t]{2}{*}{ Salt } & \multicolumn{3}{|c|}{ eCPA/This Work } & \multicolumn{3}{|c|}{ eCPA/Maribo-Mogensen et al. ${ }^{17}$} & \multicolumn{3}{|c|}{ Extended UNIQUAC ${ }^{35}$} \\
\hline & $\gamma^{ \pm}(\%)$ & $\phi(\%)$ & Sol. (\%) & $\gamma^{ \pm}(\%)$ & $\phi(\%)$ & Sol. (\%) & $\gamma^{ \pm}(\%)$ & $\phi(\%)$ & Sol. (\%) \\
\hline $\mathrm{NaCl}$ & $3.09(2.82)$ & $1.45(1.38)$ & 1.43 & $2.38(2.21)$ & $1.62(1.50)$ & 2.34 & 2.88 & 1.83 & 1.23 \\
\hline $\mathrm{NaBr}$ & $10.17(8.30)$ & $3.97(3.97)$ & 3.87 & $7.51(6.56)$ & $4.19(4.19)$ & 4.75 & 9.55 & 2.37 & 3.00 \\
\hline $\mathrm{Na}_{2} \mathrm{SO}_{4}$ & $5.55(3.72)$ & $3.02(2.07)$ & 2.06 & $4.88(3.05)$ & $2.22(2.03)$ & 4.79 & 3.09 & 2.58 & 3.97 \\
\hline $\mathrm{NaNO}_{3}$ & $9.80(9.80)$ & $6.18(6.18)$ & 2.99 & $5.89(5.89)$ & $3.89(3.89)$ & 17.5 & 4.10 & 1.23 & 2.72 \\
\hline $\mathrm{KCl}$ & $7.32(1.56)$ & $3.41(1.14)$ & 1.30 & $3.48(0.89)$ & $1.98(0.75)$ & 4.15 & 1.28 & 1.44 & 1.06 \\
\hline $\mathrm{KBr}$ & $10.20(3.26)$ & $0.80(0.81)$ & 2.06 & $4.93(2.33)$ & $0.71(0.70)$ & 6.55 & 10.95 & 3.30 & 3.34 \\
\hline $\mathrm{K}_{2} \mathrm{SO}_{4}$ & $2.86(2.34)$ & $2.04(1.66)$ & 2.67 & $3.06(3.06)$ & $1.82(1.33)$ & 5.05 & 3.58 & 2.49 & 3.00 \\
\hline $\mathrm{KNO}_{3}$ & $1.75(1.75)$ & $5.85(5.85)$ & 4.04 & $0.43(0.43)$ & $5.80(5.80)$ & 17.04 & 2.67 & 2.62 & 4.99 \\
\hline $\mathrm{MgCl}_{2}$ & 11.60 (10.97) & 7.31 (7.69) & 2.29 & 16.91 (15.79) & $7.01(7.83)$ & - & 11.76 & 5.95 & 1.60 \\
\hline $\mathrm{MgBr}_{2}$ & $13.44(13.44)$ & $7.50(7.50)$ & 2.88 & $12.12(12.12)$ & $7.74(7.74)$ & - & 16.45 & 6.65 & 2.93 \\
\hline $\mathrm{MgSO}_{4}$ & $10.54(10.54)$ & $7.82(6.97)$ & 6.83 & $11.50(11.50)$ & 7.89 (7.28) & 30.31 & 11.65 & 8.29 & 2.93 \\
\hline $\mathrm{Mg}\left(\mathrm{NO}_{3}\right)_{2}$ & 7.92 (7.92) & $4.83(4.83)$ & 3.54 & 7.87 (7.87) & $2.73(2.73)$ & - & 5.54 & 8.58 & 3.17 \\
\hline Average & $7.87(6.37)$ & $4.55(4.17)$ & 2.99 & $6.78(5.98)$ & $4.02(3.81)$ & 10.28 & 6.96 & 3.94 & 2.83 \\
\hline
\end{tabular}


Table 6: Standard State properties for the investigated solid salts. On the left side are the properties fitted in this work. On the right side are values used as initial estimate adapted from the Extended UNIQUAC ${ }^{8}$. * indicates a fitted value in this work. Non-fitted values are taken from Wagman ${ }^{48}$, and heat capacities are calculated from equation (24).

\begin{tabular}{|c|c|c|c|c|c|c|}
\hline \multirow[t]{2}{*}{ Salt } & \multicolumn{3}{|l|}{ This Work } & \multicolumn{3}{|c|}{ Extended UNIQUAC database ${ }^{35}$} \\
\hline & $\begin{array}{r}\Delta_{\text {form }} G \\
(\mathbf{k J} / \mathbf{m o l})\end{array}$ & $\begin{array}{r}\Delta_{\text {form }} H \\
(\mathbf{k J} / \mathbf{m o l})\end{array}$ & $\begin{array}{c}C_{P}^{0} \\
(J / \mathrm{mol} / \mathrm{K})\end{array}$ & $\underset{(\mathrm{kJ} / \mathrm{mol})}{\Delta_{\text {form }} \boldsymbol{G}}$ & $\begin{array}{r}\Delta_{\text {form }} H \\
(\mathrm{~kJ} / \mathrm{mol})\end{array}$ & $\begin{array}{c}C_{P}^{0} \\
(J / \mathrm{mol} / \mathrm{K})\end{array}$ \\
\hline $\mathrm{NaCl}$ & -384.1 & -411.2 & 50.5 & -384.1 & -411.2 & 50.5 \\
\hline $\mathrm{NaCl} \cdot 2 \mathrm{H}_{2} \mathrm{O}$ & $-859.3^{*}$ & $-987.4^{*}$ & 230.1 & -859.0 & 992.5 & 230.1 \\
\hline $\mathrm{NaBr}$ & -350.0 & -361.6 & 51.4 & -350.0 & -361.6 & 51.4 \\
\hline $\mathrm{NaBr} \cdot 2 \mathrm{H}_{2} \mathrm{O}$ & $-828.3^{*}$ & $-951.9 *$ & 131.4 & -829.0 & -948.2 & 131.4 \\
\hline $\mathrm{NaBr} \cdot 5 \mathrm{H}_{2} \mathrm{O}$ & $-1539.8 *$ & $-1823.5^{*}$ & 251.4 & -1536.9 & -1834.5 & 251.4 \\
\hline $\mathrm{Na}_{2} \mathrm{SO}_{4}$ & -1270.2 & -1387.1 & 128.2 & -1270.2 & -1387.1 & 128.2 \\
\hline $\mathrm{Na}_{2} \mathrm{SO}_{4} \cdot 10 \mathrm{H}_{2} \mathrm{O}$ & $-3646.9 *$ & $-4319.9 *$ & 492.2 & -3646.9 & -4327.2 & 492.2 \\
\hline $\mathrm{NaNO}_{3}$ & -367.0 & -467.9 & 92.9 & -367.0 & -467.9 & 92.9 \\
\hline $\mathrm{KCl}$ & -409.1 & -436.4 & 51.3 & -409.1 & -436.4 & 51.3 \\
\hline $\mathrm{KBr}$ & -381.1 & -393.8 & 52.3 & -381.1 & -393.8 & 52.3 \\
\hline $\mathrm{K}_{2} \mathrm{SO}_{4}$ & -1321.4 & -1437.8 & 131.5 & -1321.4 & -1437.8 & 131.5 \\
\hline $\mathrm{KNO}_{3}$ & -394.9 & -494.6 & 96.4 & -394.9 & -494.6 & 96.4 \\
\hline $\mathrm{MgCl}_{2} \cdot 2 \mathrm{H}_{2} \mathrm{O}$ & $-1150.7^{*}$ & $-1367.5^{*}$ & 151.4 & -1118.0 & -1279.2 & 159.2 \\
\hline $\mathrm{MgCl}_{2} \cdot 4 \mathrm{H}_{2} \mathrm{O}$ & $-1636.3^{*}$ & $-1930.7^{*}$ & 231.4 & -1638.0 & -1927.3 & 241.4 \\
\hline $\mathrm{MgCl}_{2} \cdot 6 \mathrm{H}_{2} \mathrm{O}$ & $-2119.0 *$ & $-2504.1^{*}$ & 311.4 & -2118.2 & -2498.7 & 391.2 \\
\hline $\mathrm{MgCl}_{2} \cdot 8 \mathrm{H}_{2} \mathrm{O}$ & $-2595.8^{*}$ & $-3090.3^{*}$ & 391.4 & -2594.8 & -3088.7 & 391.0 \\
\hline $\mathrm{MgCl}_{2} \cdot 12 \mathrm{H}_{2} \mathrm{O}$ & $-3547.4^{*}$ & $-4257.4^{*}$ & 551.4 & -3546.5 & -4261.0 & 551.0 \\
\hline $\mathrm{MgBr} \cdot 6 \mathrm{H}_{2} \mathrm{O}$ & $-2062.9 *$ & $-2420.2^{*}$ & 336.1 & - & - & - \\
\hline $\mathrm{MgBr} \cdot 9 \mathrm{H}_{2} \mathrm{O}$ & $-2778.5^{*}$ & $-3294.0 *$ & 456.1 & - & - & - \\
\hline $\mathrm{MgBr} \cdot 10 \mathrm{H}_{2} \mathrm{O}$ & $-3017.0 *$ & $-3579.3 *$ & 496.1 & - & - & - \\
\hline $\mathrm{MgSO}_{4} \cdot \mathrm{H}_{2} \mathrm{O}$ & $-1433.6^{*}$ & $-1602.5^{*}$ & 98.1 & -1435.8 & -1605.8 & 98.1 \\
\hline $\mathrm{MgSO}_{4} \cdot 6 \mathrm{H}_{2} \mathrm{O}$ & $-2632.2^{*}$ & $-3097.5^{*}$ & 421.2 & -2631.1 & -3086.8 & -421.2 \\
\hline $\mathrm{MgSO}_{4} \cdot 7 \mathrm{H}_{2} \mathrm{O}$ & $-2870.4^{*}$ & $-3391.8^{*}$ & 247.5 & -2869.4 & -3382.1 & 247.5 \\
\hline $\mathrm{MgSO}_{4} \cdot 12 \mathrm{H}_{2} \mathrm{O}$ & $-4056.2^{*}$ & $-4829.8^{*}$ & 576.0 & -4054.8 & -4823.0 & 576.0 \\
\hline $\mathrm{Mg}\left(\mathrm{NO}_{3}\right)_{2} \cdot 2 \mathrm{H}_{2} \mathrm{O}$ & $-1113.7^{*}$ & $-1482.8^{*}$ & 221.9 & -1117.5 & -1506.4 & 1031.7 \\
\hline $\mathrm{Mg}\left(\mathrm{NO}_{3}\right)_{2} \cdot 6 \mathrm{H}_{2} \mathrm{O}$ & $-2084.0 *$ & $-2602.4^{*}$ & 381.9 & -2086.4 & -2613.4 & 313.4 \\
\hline $\mathrm{Mg}\left(\mathrm{NO}_{3}\right)_{2} \cdot 9 \mathrm{H}_{2} \mathrm{O}$ & $-2797.1^{*}$ & $-3474.0 *$ & 501.9 & -2797.4 & -3488.0 & 502.0 \\
\hline
\end{tabular}



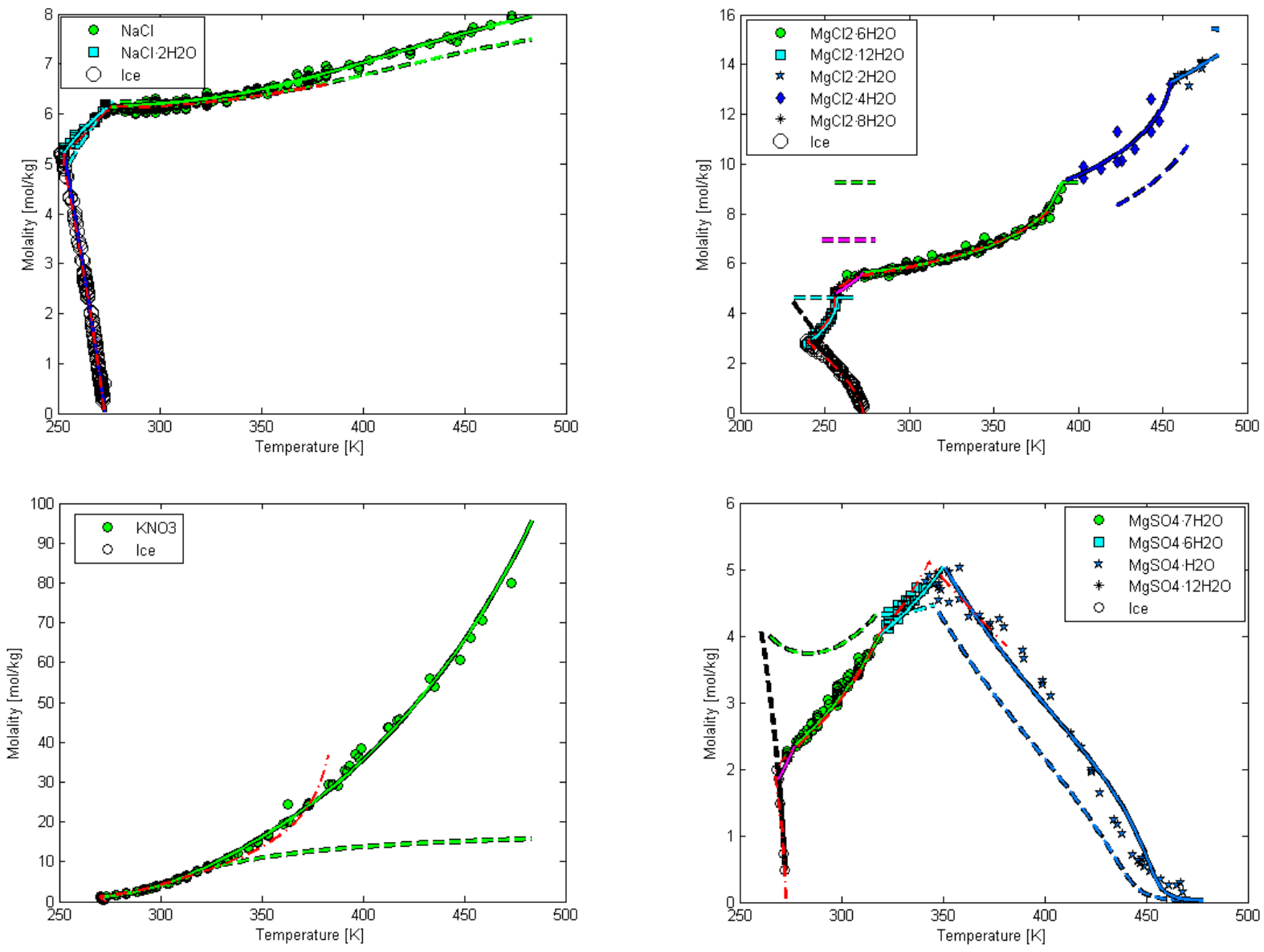

Figure 1: Freezing point and solubility as a function of temperature, on the top left for a $\mathrm{NaCl}$ solution, on the top right for a $\mathrm{MgCl}_{2}$ solution, on the bottom left for $\mathrm{KNO}_{3}$, and on the bottom right for $\mathrm{MgSO}_{4}$. Symbols are experimental data. Solid lines are this work, and dashed lines are Maribo-Mogensen et al. eCPA calculations using Extended UNIQUAC standard state properties. Colors and symbols changes color and shape depending on the precipitating salt. Red dashed-dot lines are Extended UNIQUAC modelling. 

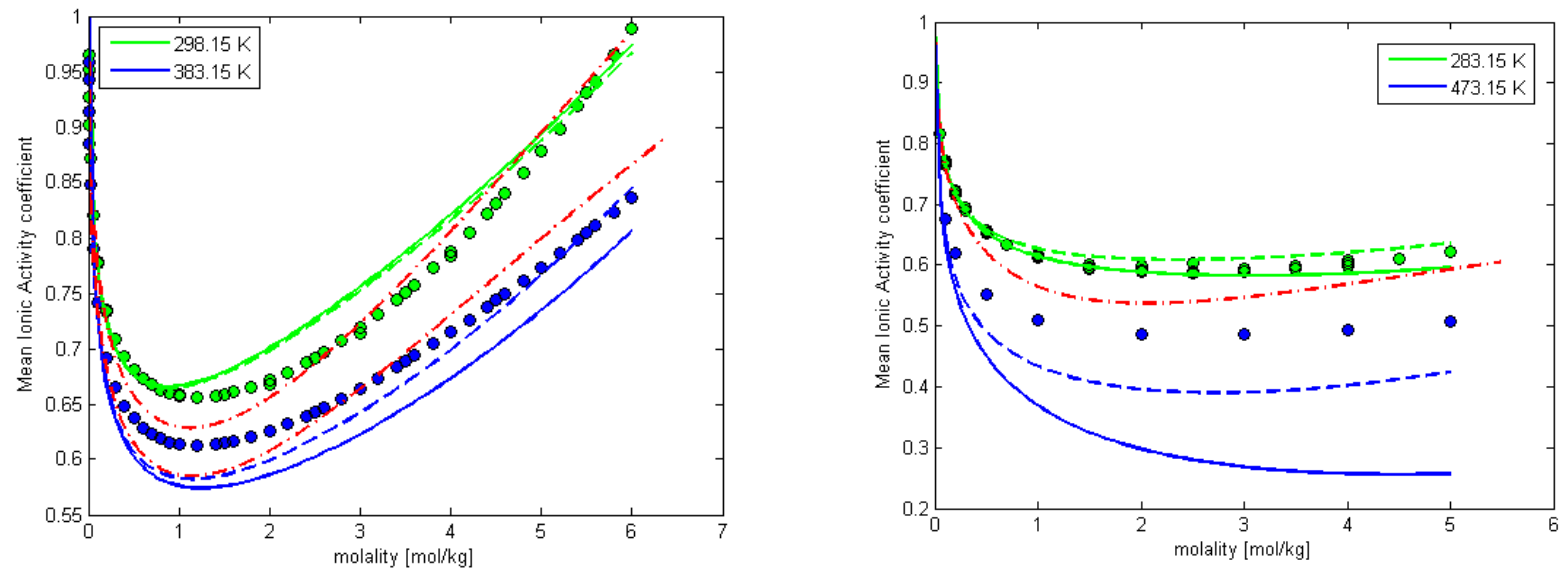

Figure 2: Mean ionic activity coefficient as a function of salt molality. On the left for $\mathrm{NaCl}$, on the right for $\mathrm{KBr}$. Symbols are experimental data. Solid lines are eCPA from this work, and dashed lines are Maribo-Mogensen et al. eCPA calculations. The color changes depending on temperature. Red dashed-dot lines are Extended UNIQUAC modelling.
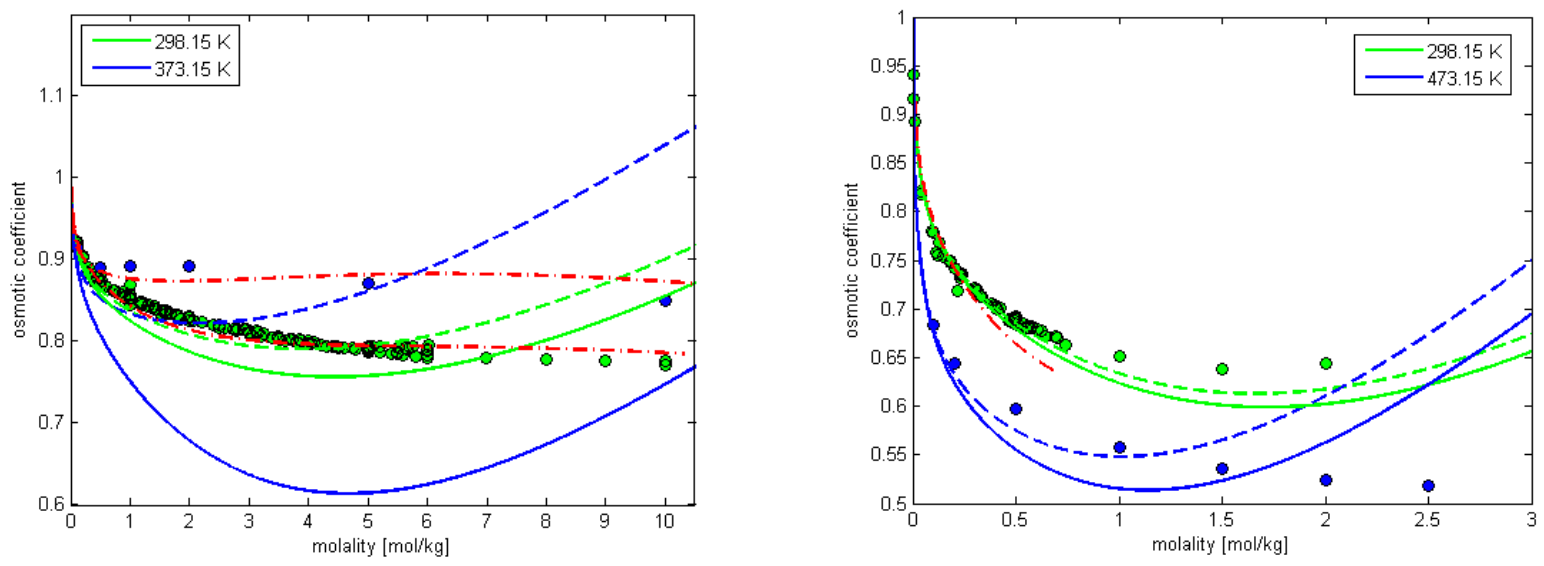

Figure 3: Osmotic coefficient as a function of salt molality. On the left for $\mathrm{NaNO}_{3}$, on the right for $\mathrm{K}_{2} \mathrm{SO}_{4}$. Symbols are experimental data. Solid lines are eCPA from this work, and dashed lines are Maribo-Mogensen et al. eCPA calculations. The color changes depending on temperature. Red dashed-dot lines are Extended UNIQUAC modelling. 
The two eCPA parameterizations generally perform very well and similarly at temperatures around 298.15 K, while the accuracy and similarities between the two parameterizations typically reduces at higher temperatures, as can be seen in Figures 2 and 3. In Figure 2 the mean ionic activity coefficient for $\mathrm{NaCl}$, and $\mathrm{KBr}$ is shown. In the $\mathrm{NaCl}$ plot there certainly is a difference between the two parameterizations at the higher temperature, but it is small compared to differences and deviations seen at the high temperature in the $\mathrm{KBr}$ plot.

In addition to the two Bromide salts which showed high deviations for the activity coefficient, the two nitrate salts investigated also show significant increase in deviations with the new parameters, for both osmotic and mean ionic activity coefficients. This is illustrated in Figure 3, where the osmotic coefficient of $\mathrm{NaNO}_{3}$ is shown. As for $\mathrm{KBr}$, the difference between the two parameterizations and deviations are minor at $298.15 \mathrm{~K}$ but significant at $373.15 \mathrm{~K}$.

In comparison to the Extended UNIQUAC model the average deviations are similar, with Extended UNIQUAC having slightly lower deviations for the mean ionic activity coefficient for most of the salts. For $\mathrm{NaCl}$ the relative average deviations for Extended UNIQUAC are very comparable to the eCPA, but when looking at Figure 2 it is clear that the two models do not follow the same path. In most cases it is observed that eCPA captures the typical minimum in activity coefficient or osmotic coefficient better at around $298.15 \mathrm{~K}$ while none of the models do so at higher temperatures.

\section{Discussion}

This work had three main objectives, namely to set up a fitting procedure that included solubility data and thus accurate solubility description for the model without sacrificing the good description of the 
osmotic and activity coefficients; to evaluate the new parameters by comparison to the original eCPA parameters of Maribo-Mogensen et al. ${ }^{17}$; and finally to compare the performance of eCPA to that of a well-documented activity coefficient model, Extended UNIQUAC. These objectives are the focus for the discussion in this section.

\subsection{Parameter Estimation}

The procedure for parameter regression proved to be complex and not as straightforward as originally anticipated. The uniform direct procedure was not applicable to all salts investigated, and thus it is not possible to write a generic step by step procedure that applies in all cases. We could divide the investigated salts in three groups. There are a number of salts, including all the potassium salts and $\mathrm{NaNO}_{3}$, which only precipitate in their anhydrous form. This group of salts is the easiest to parameterize as it was decided to use tabulated standard state properties for such solids, which means that only the energy interaction parameters were adjustable. For these salts the fitting procedure is similar to when only fitting to osmotic and activity coefficients. From the solubility diagrams calculated with the MariboMogensen et al. parameters, it was evident that the solubility description is primarily deviating for the high temperature/high solubility data, while being fairly accurate at low temperatures. In order to ensure accurate solubility description at higher temperatures the residual function was weighted higher for data points above $350 \mathrm{~K}$ for the nitrate salts as well as $\mathrm{KBr}$, while for the others there was no need to differentiate the weight of the solubility data. The nitrate salts need this different weight as they are very soluble and thus have a solubility 5-10 times higher than the other salts investigated. This means that using solubility in the fitting introduces data points at an ionic strength of 70 molal or more while 
the osmotic and activity coefficient data are found at no higher than approx. 15 molal. The need for the weight for $\mathrm{KBr}$ was evident due to trial and error investigations.

A second group of salts consists of the remaining sodium salts investigated. These salts all precipitate as hydrated salts at low temperatures, and as anhydrous salts at higher temperatures. The challenge with this group of salts is similar to the first group of salts discussed. Again, using the Maribo-Mogensen et al. parameters, the primary deviation in solubility was seen at higher temperatures, and thus most of the hydrated salt precipitation was actually fairly accurately described. As the unhydrated salts standard state properties are fixed, the deviation at the high temperature can only be accounted for by the interaction energy parameters and not by altering the standard state properties. For these salts, however, the standard state properties of the hydrated salts are treated as adjustable, which complicates somewhat the fitting procedure. The procedure is, however, not very complicated, but in addition to the model parameters the standard state properties of the hydrated salts are estimated based on a least squares optimization, simultaneously optimizing the model parameters and the standard state properties. Finally, to ensure the best possible optimization, the interaction parameters are optimized with the new standard state properties kept constant.

The final group of salts investigated is magnesium salts. The magnesium salts have more complex solubility profiles than the remaining salts investigated. All four salts precipitate in several hydrated forms only occurring in limited temperature ranges, but not in their anhydrous form, at least within the experimental data range we have used. For three of the salts, $\mathrm{MgCl}, \mathrm{MgBr}$ and $\mathrm{Mg}\left(\mathrm{NO}_{3}\right)_{2}$ calculating the solubility with the original parameters of Maribo-Mogensen et al. ${ }^{17}$ was not possible, as the calculations fail to converge. The optimization routine for these salts is, due to the complexity with 
several hydrated salts, more complex in order to converge to a reasonable set of parameters. For $\mathrm{MgCl}_{2}$, the routine is slightly simpler than for the two other salts, as in this case it is sufficient to first optimize model parameters with constant standard state properties. This step is followed by optimization of the standard state properties with constant model parameters, and finally an optimization of the model parameters again for fine tuning. For the three other salts, $\mathrm{MgCl}_{2}, \mathrm{MgBr}_{2}$ and $\mathrm{Mg}\left(\mathrm{NO}_{3}\right)_{2}$, a much more complex optimization routines are employed. For these three salts several different routines have been tried, including simultaneous optimization of all parameters, fitting only the standard state properties without changing the original eCPA parameters of Maribo-Mogensen et al. etc. Alternating between estimating the eCPA interaction energy and temperature dependency parameters, and the standard state properties was found to be the best option. This process is illustrated in Figure 4, with the MariboMogensen et al. parameters as an initial estimate (step 1), the process is started by initially adjusting the standard state properties to the solubility data, with the eCPA parameters of Maribo-Mogensen et al. set constant (step 2), followed by an estimation of the eCPA parameters with the newly estimated standard state properties set constant (step 3). With these new eCPA parameters set constant, the standard state properties are once again estimated (back to step 2), followed again by estimation of the eCPA parameters with the new standard state properties set constant (step 3). This iterative loop is run at least twice and until the change in residuals of step 3 (Figure 4) between two iterations is (virtually) unchanged, and thus converged. 


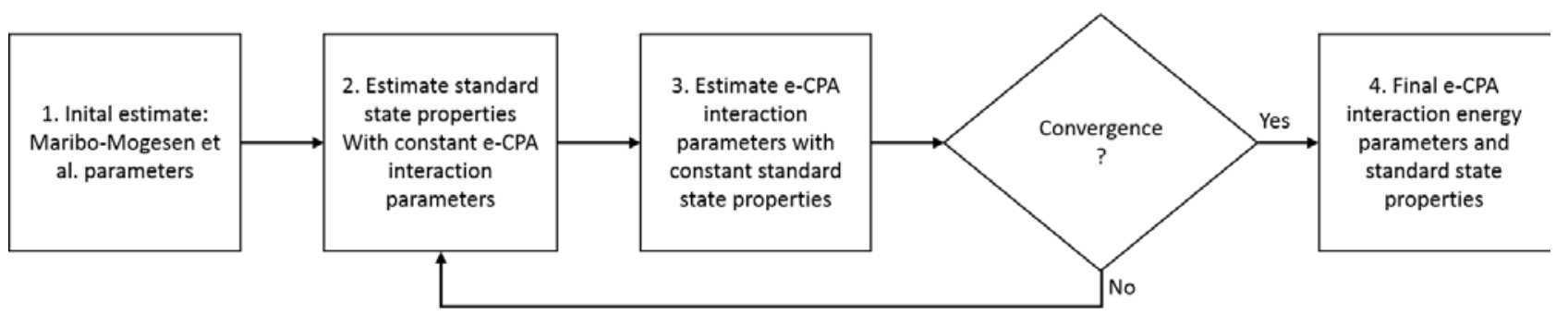

Figure 4: Illustration of the parameter estimation procedure used for $\mathrm{MgCl}_{2}$ and $\mathrm{MgBr}_{2}$.

\subsection{Born Radius}

In the parameter estimation process, the Born radius was adopted from the original parameters of Maribo-Mogensen et al. ${ }^{17}$ under the assumption that the change in other model parameters would have little effect on the model's ability to accurately calculate the enthalpy of hydration (as introduced in section 2.3). To validate this assumption, the hydration enthalpy is calculated and compared to the data from which the Born radius was originally estimated (salt hydration enthalpy derived from Wagman et al. ${ }^{48}$ ). As can be seen in Table 7 the absolute relative deviation in hydration enthalpy with the parameters of this work is very low, with an average deviation of $0.5 \%$, while the deviation with the original parameters of Maribo-Mogensen et al., where the radius was fitted to match the data, is only slightly lower with an average of $0.43 \%$. This indicates that the assumption was indeed valid and that it is viable to use these values without doing a refitting of the Born radius. 
Table 7: Hydration enthalpy data for each salt, calculated from Wagman et al. ${ }^{48}$, along with eCPA calculations of the hydration enthalpy, using both the parameters of this work and those of MariboMogensen et al. ${ }^{17}$. Furthermore the absolute relative deviations (Abs. Rel. Dev.) are listed.

\begin{tabular}{|c|c|c|c|c|c|}
\hline \multirow[b]{2}{*}{ Salts } & \multirow{2}{*}{$\begin{array}{c}\text { Wagman et al. }{ }^{48} \\
\boldsymbol{\Delta}_{\text {hyd }} \boldsymbol{H} \\
(\mathrm{kJ} / \mathrm{mol})\end{array}$} & \multicolumn{2}{|c|}{ This Work } & \multicolumn{2}{|c|}{ Maribo-Mogensen et al. ${ }^{17}$} \\
\hline & & $\begin{array}{c}\Delta_{\text {hyd }} H(\mathrm{eCPA}) \\
(\mathrm{kJ} / \mathrm{mol})\end{array}$ & $\begin{array}{c}\text { Abs. Rel. Dev. } \\
(\%)\end{array}$ & $\begin{array}{c}\Delta_{\text {hyd }} H(\mathrm{eCPA}) \\
(\mathrm{kJ} / \mathrm{mol})\end{array}$ & $\begin{array}{c}\text { Abs. Rel. Dev. } \\
(\%)\end{array}$ \\
\hline $\mathrm{NaCl}$ & -788.020 & -795.772 & 0.98 & -793.029 & 0.64 \\
\hline $\mathrm{NaBr}$ & -751.954 & -752.24 & 0.04 & -749.253 & 0.35 \\
\hline $\mathrm{Na}_{2} \mathrm{SO}_{4}$ & -1973.665 & -1986.101 & 0.63 & -1981.445 & 0.39 \\
\hline $\mathrm{NaNO}_{3}$ & -750.678 & -754.542 & 0.51 & -751.832 & 0.15 \\
\hline $\mathrm{KCl}$ & -705.179 & -713.418 & 1.17 & -710.322 & 0.73 \\
\hline $\mathrm{KBr}$ & -669.113 & -669.882 & 0.12 & -666.545 & 0.38 \\
\hline $\mathrm{K}_{2} \mathrm{SO}_{4}$ & -1807.983 & -1821.393 & 0.74 & 1816.03 & 0.45 \\
\hline $\mathrm{KNO}_{3}$ & -667.837 & -672.188 & 0.65 & -669.124 & 0.19 \\
\hline $\mathrm{MgCl}_{2}$ & -2692.437 & -2691.675 & 0.02 & -2687.333 & 0.19 \\
\hline $\mathrm{MgBr}_{2}$ & -2620.304 & -2604.603 & 0.6 & -2599.779 & 0.78 \\
\hline $\mathrm{MgSO}_{4}$ & -3090.062 & -3086.232 & 0.12 & -3082.719 & 0.24 \\
\hline $\mathrm{Mg}\left(\mathrm{NO}_{3}\right)_{2}$ & -2617.75 & -2628.179 & 0.40 & -2635.461 & 0.68 \\
\hline Average & & & 0.50 & & 0.43 \\
\hline
\end{tabular}

\subsection{Model Performance}

As the model is parameterized to correlate the solubility as accurately as possible, it is of interest to evaluate what effect the solubility correlation has on the other properties $\left(\gamma^{ \pm}, \phi\right)$. The relative average deviations seen in Table 5 indicate that the performance with regards to osmotic coefficient and activity coefficient is only slightly worse with the parameters of this work compared to the Maribo-Mogensen et al. parameters. Behind such average numbers is, however, a more complex picture. For all salts it was found that the deviations were not constant with temperature, and that applies for both eCPA 
parameterizations. Generally, the model performs very well at $298.15 \mathrm{~K}$ and often in a temperature range around $298.15 \mathrm{~K}$. The accurate performance at around $298.15 \mathrm{~K}$ and the surrounding temperature range is believed to be due to the type of the temperature dependency in use. The temperature dependence (equation (15)) has a reference interaction energy calculated at the reference temperature, which is set to $298.15 \mathrm{~K}$. This means that there is a parameter directly related to 298.15 $\mathrm{K}$, while the two remaining parameters of the temperature dependency are supposed to account for the remaining temperatures. As it is observed, the Maribo-Mogensen et al. parameters could predict the solubility at $298.15 \mathrm{~K}$ with a reasonable accuracy, it would thus, not be expected that the reference interaction energy would change much. This is also what is observed in Table 4, where the difference between the reference energy is small compared to the much more significant difference in the $\alpha$ parameter observed for some salts. For $\mathrm{NaCl}$, even though the $\alpha$ parameter is only changed slightly, the impact on the performance is clear both from Figure 2, and especially from Figure 5. In Figure 5 the relative average deviation is shown as a function of temperature for both osmotic coefficient and activity coefficient. From these plots it is evident that the osmotic coefficient description is similar for the two parameterizations and acceptable in the entire temperature range, except for the very highest temperatures and molalities. An issue with high molality high temperature representation is observed as large deviations are found for both parameterizations at these conditions while deviations below 6 molal are still low. The activity coefficients, however, deviate less uniform with temperature for both parameterizations, with low deviations only found in the temperature range: $290-350 \mathrm{~K}$. The more stable deviations of the osmotic coefficient, up until very high temperatures are common for almost all 
salts, however, many have a slight change towards higher deviations at the highest investigated temperatures.
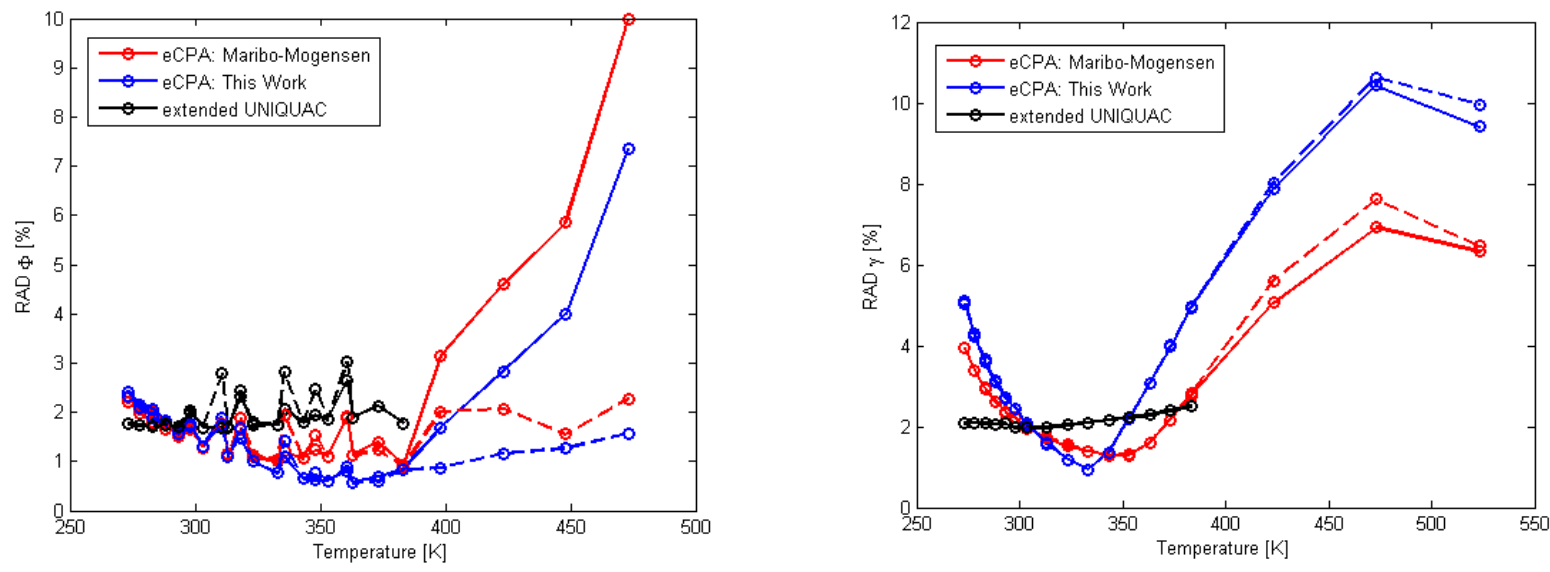

Figure 5: Relative average deviation (RAD) of osmotic coefficient (left) and Mean ionic activity coefficient (right) for $\mathrm{NaCl}$ as a function of temperature. Solid lines are deviations for full data set, and dashed lines are deviations for data up to an ionic strength of 6 molal.

For the nitrate salts the osmotic coefficient description is significantly worse with the new parameters, especially at high temperatures, as evident from Figure 6. For these salts, high deviations, both overall and particularly at the higher temperatures, are observed with the parameters of this work. This is believed to be due to the very high solubility of the nitrate salts, the highest molality of a solubility data point being 80 molal at $473.15 \mathrm{~K}$. These are much higher than the molalities of the osmotic coefficient data used. Forcing the model to accurately describe the solubility, is distorting the presentation of the osmotic coefficients. The parameters in Table 4 support this as well, as the $\alpha$ parameter, which scales the quadratic function of the temperature dependence, changes from values in the hundreds to more 
than three thousand. Deviations of similar magnitude as those found for the nitrate salts are seen for the magnesium salts. Still the increase in deviation compared to the Maribo-Mogensen et al. parameters is not as significant for magnesium salts.
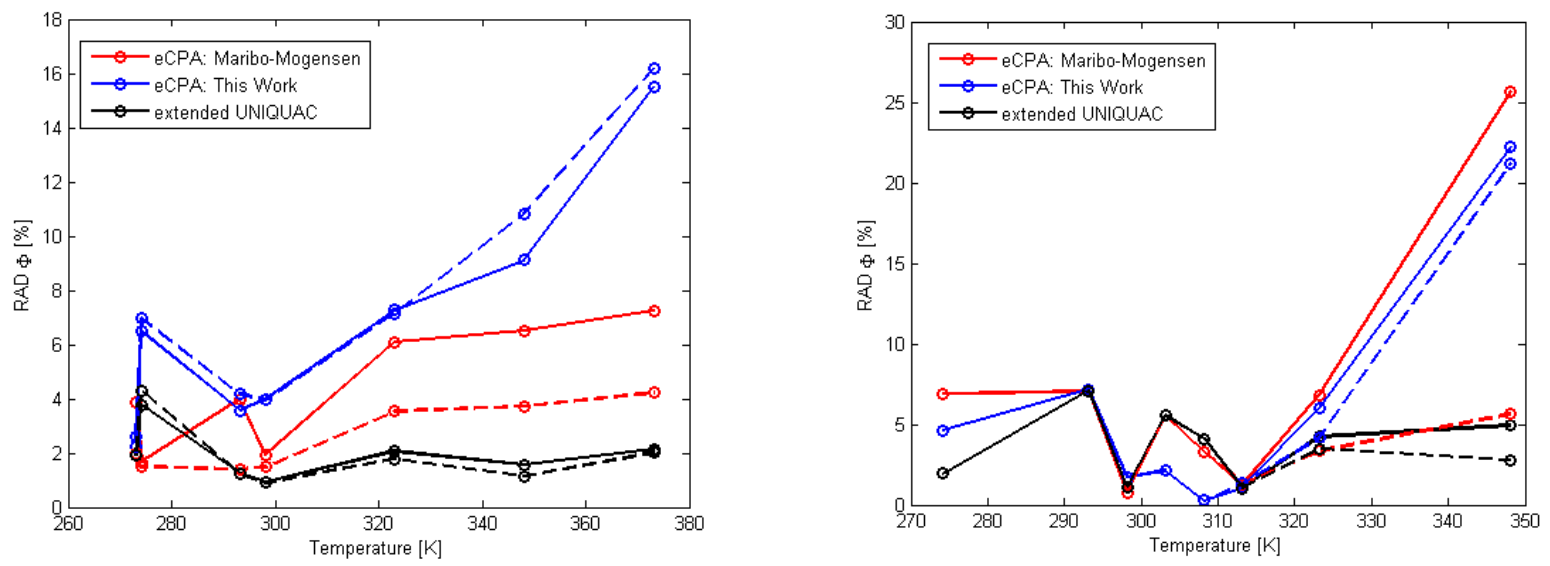

Figure 6: Relative average deviation (RAD) of osmotic coefficient for $\mathrm{NaNO}_{3}$ (left) and $\mathrm{KNO}_{3}$ (right). Solid lines are deviations for full data set, and dashed lines are deviations for data up to an ionic strength of 6 molal.

The deviations of the activity coefficients are not uniform with regards to temperature, as exemplified for $\mathrm{NaCl}$ and $\mathrm{K}_{2} \mathrm{SO}_{4}$ in Figures 5 and 7, which only show low deviation in a relatively narrow temperature range. For some salts, the deviation profile with higher deviations at higher temperatures was already prominent with the original parameter set. It is also clear that the solubility inclusion magnifies this tendency significantly, as is the case with $\mathrm{NaCl}$ (see Figure 5). For other salts, such as $\mathrm{K}_{2} \mathrm{SO}_{4}$, uniform deviations with regards to temperatures are found with the original parameters, but with the parameters of this work the deviations are not uniform either. 
From the Figures 5 to 7 it is evident that the models' biggest challenge is high molality, high temperature calculations. For all salts where data above an ionic strength of 6 is available there is a big difference between deviations of the data below 6 molal and the full data set. The parameterization of MariboMogensen et al. shows clearly that the model performs well within the molality range for which it has been parameterized, however, above this, especially at high temperatures, it fails. Including the high molality data (both solubility and others) in the fitting shows to improve high temperature representation in some cases, for the full data set. However below 6 molal the solubility data generally impact the osmotic coefficient and mean ionic activity coefficient negatively, producing high deviations below 6 molal. High molality data is in many studies excluded, with the data typically limited to 5-8 molal ${ }^{12,15}$. This limit is believed to be due to the models difficulty in representing the high molality data, and thus it might be set as a limit of application. In a study where solubility data is included it does, however, not make sense to limit the molality of one type of data while another type is found at higher molalities and thus in this work osmotic coefficient and mean ionic activity coefficients are used up to the solubility limit. 

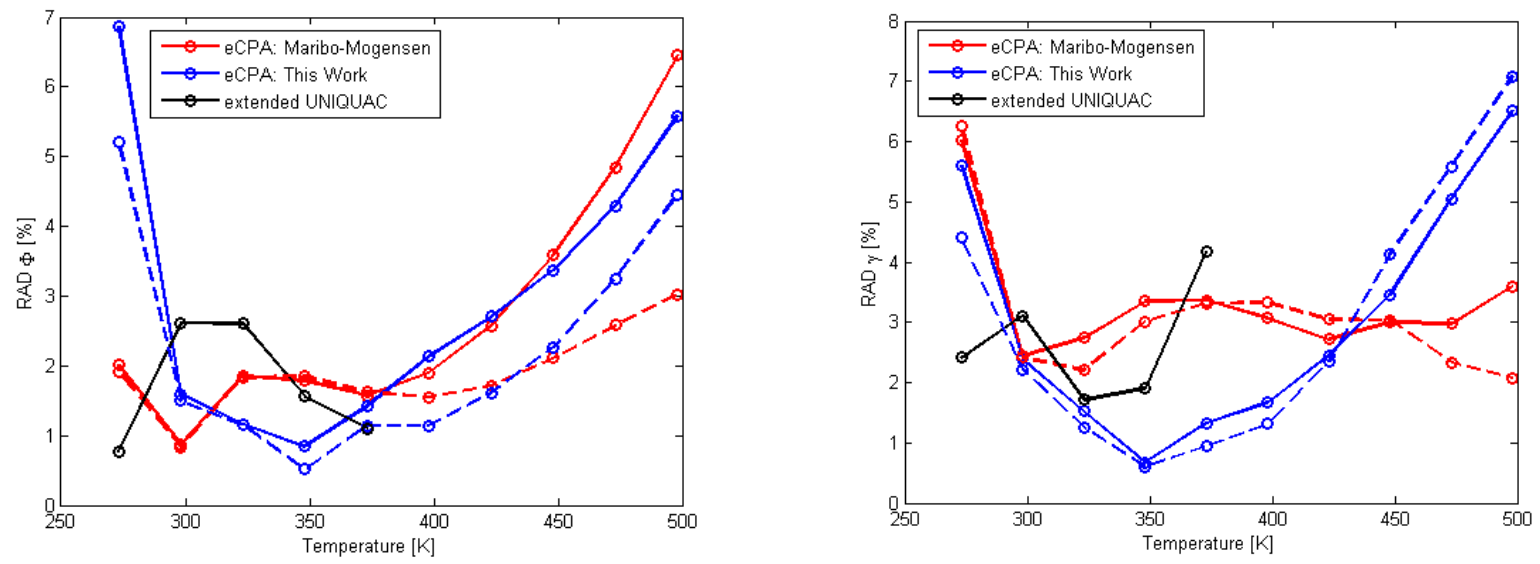

Figure 7: Relative average deviation of osmotic coefficient (left) and mean ionic activity coefficient (right) for $\mathrm{K}_{2} \mathrm{SO}_{4}$ as a function of temperature. Solid lines are deviations for full data set, and dashed lines are deviations for data up to an ionic strength of 6 molal.

The fact that the impact of including the solubility is far more severe for the activity coefficient than it is for the osmotic coefficient contradicts the relationship between the two properties. The GibbsDuhem equation (equation (25)) links the two and thus the models performance should be similar between the two properties. The integral within the equations does, however, indicate that the mean ionic activity coefficient is more sensitive to the parameters, something that has also been noted by other authors ${ }^{11,50}$. The lower deviations for the osmotic coefficient is therefore most likely due to a lower sensitivity to parameters for the osmotic coefficient than for the mean ionic activity coefficient.

For most of the sodium and potassium salts the solubility is accurately predicted up to approximately $350 \mathrm{~K}$, with the Maribo-Mogensen et al. parameters, the nitrate salts excluded due to the very high solubility. The change in parameters between the two parameterizations is, thus, primarily to correct 
the solubility above $350 \mathrm{~K}$. Above this temperature most of the salts precipitate in the anhydrous form, and thus the standard state properties of solids are fixed to tabulated values from Wagman et al. ${ }^{48}$. One solution to correct the non-uniform deviations of the osmotic coefficient and especially the mean ionic activity coefficient with regards to temperature, for salt what show that behavior with the parameters of this work, while not with the parameters of Maribo-Mogensen et al., could be to fit the solid standard state properties of the unhydrated salts as well. For instance if this was done for $\mathrm{KCl}$, accurate solubility correlation (RAD: $1.87 \%$ ) can be obtained, which is similar to the deviation with the parameters presented in this work (RAD: 1.30\%). As seen from Figure 8, the effect on the osmotic coefficient and mean ionic activity coefficient of fitting the standard state properties as well, is significantly better correlation of the properties at high temperature, contributing to overall lower deviations as evident from Table 8.
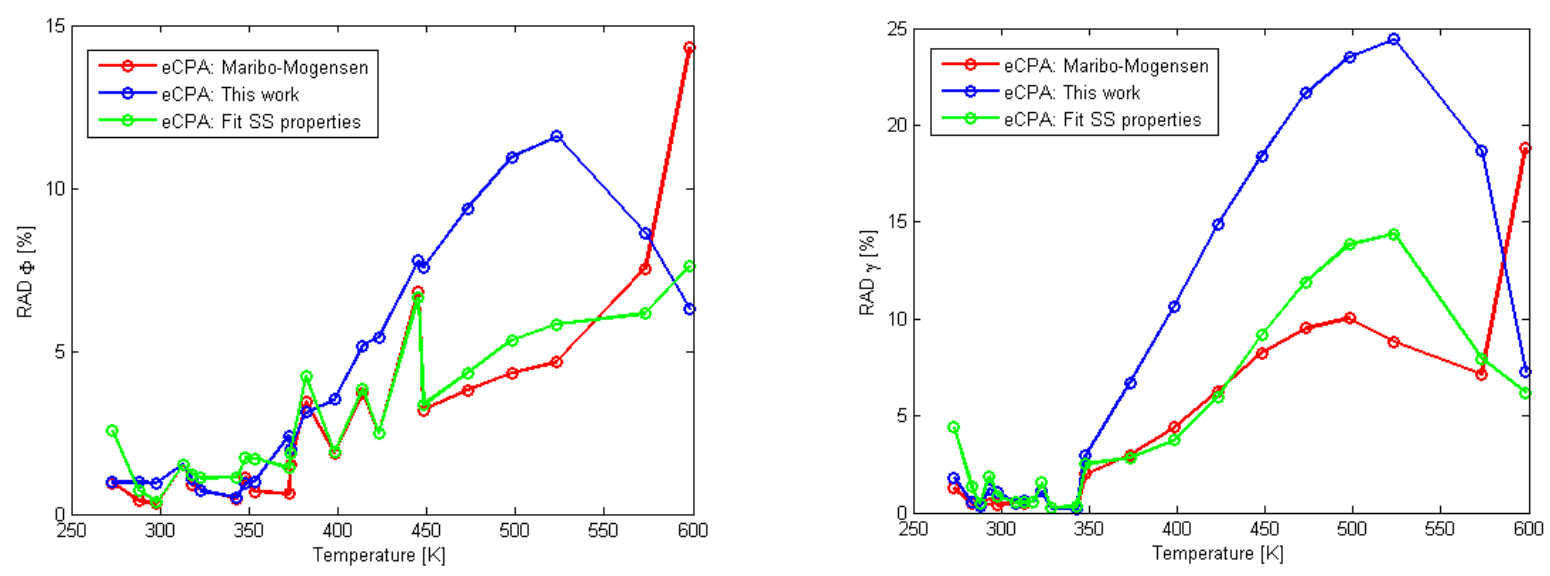

Figure 8: Relative average deviation of osmotic coefficient (left) and mean ionic activity coefficient (right) for $\mathrm{KCl}$ as a function of temperature, with three parameterizations of eCPA. The new parameter set had the solid standard state (SS) properties as adjustable along with the eCPA interaction energy parameters. 
Table 8: Comparison between eCPA parameterizations, showing the eCPA interaction energy parameters, the solid standard state properties, and the deviations for osmotic coefficient and mean ionic activity coefficient

\begin{tabular}{l|ccc|ccc|cc}
\hline Parameterization & $\boldsymbol{\Delta} \boldsymbol{U}_{\boldsymbol{r e f}} / \boldsymbol{R}$ & $\boldsymbol{\alpha}$ & $\boldsymbol{T}_{\boldsymbol{\alpha}}$ & $\boldsymbol{\Delta}_{\text {form }} \boldsymbol{G}$ & $\boldsymbol{\Delta}_{\text {fom }} \boldsymbol{H}$ & $\boldsymbol{C}_{\boldsymbol{P}}^{\mathbf{0}}$ & \multicolumn{2}{c}{ RAD } \\
for KCl & $\mathbf{Q 2 5}^{\circ} \mathbf{C}(\mathbf{K})$ & $(\mathbf{K})$ & $\mathbf{( K )}$ & $(\mathbf{k J} / \mathbf{m o l})$ & $(\mathbf{k J} / \mathbf{m o l})$ & $(\boldsymbol{J} / \mathbf{m o l} / \mathbf{K})$ & $\boldsymbol{\phi}(\%)$ & $\boldsymbol{\gamma}^{ \pm}(\%)$ \\
\hline Maribo-Mogensen et al. & -129.99 & 340.0 & 1361.5 & -409.14 & -436.74 & 51.3 & 1.98 & 3.48 \\
This work & -137.36 & 324.2 & 1483.6 & -409.14 & -436.74 & 51.3 & 3.31 & 7.32 \\
Fit standard state prop. & -125.86 & 345.7 & 1740.6 & -409.40 & -441.73 & 51.3 & 2.27 & 4.31 \\
\hline
\end{tabular}

The change in the standard state properties is small, as the Gibbs energy of formation would be virtually unchanged, and the enthalpy of formation would change $5.57 \mathrm{~kJ} / \mathrm{mol}$, corresponding to an approximate change of $1.2 \%$. Even though using this tool to obtain accurate solubility description without losing significant accuracy for the activity coefficients could work, it would result in a more empirical implementation of the model, and it was therefore not considered further.

\subsection{Model Comparison}

The comparison with the Extended UNIQUAC model indicates that the two models overall perform similarly. The Extended UNIQUAC is limited to $383.15 \mathrm{~K}$ as described by the authors of the mode $\mathrm{l}^{35}$, and in that temperature range the solubility is accurately correlated to the same accuracy as with the eCPA with parameters of this work. Trends of the solubility near $383.15 \mathrm{~K}$ suggest that extrapolation is not accurate for some of the salts at least with regards to solubility. With regards to osmotic coefficients and mean ionic activity coefficients the average deviations of Extended UNIQUAC is slightly higher than those of eCPA with Maribo-Mogensen et al. parameters, and very similar to those of eCPA with 
parameters of this work. As eCPA with Maribo-Mogensen et al. parameters does not include solubility in the parameters estimation it is reasonable that the other properties is thus slightly better correlated, while both Extended UNIQUAC and eCPA with parameters of this work include also solubility in the parameter estimation. The clear advantage of the Extended UNIQUAC over the two eCPA parameterizations seems to be the uniform deviations with regards to temperature, in the entire temperature range where the Extended UNIQUAC is valid (up to $383.15 \mathrm{~K}$ ). In this range the deviations are more uniform with regards to temperature compared to especially the eCPA parameterization of this work.

Comparing the models, it is seen, for instance in Figure 1 that eCPA can better correlate the minimum in the activity coefficient and osmotic coefficient often seen, at least at $298.15 \mathrm{~K}$ where the model generally performs best. This indicates that the physics behind the eCPA may be superior to the Extended UNIQUAC. Whereas eCPA is based on the full Debye-Hückel theory, Extended UNIQUAC is based on the extended Debye-Hückel, which is a simplification. This may be a partial explanation.

As described the only other work that, to our knowledge, utilizes solubility for parameter estimation, is that of Lin et al. ${ }^{18}$. This contains a parameterization of an electrolyte CPA with MSA as the electrostatic contribution at $298.15 \mathrm{~K}$. This was parameterized with and without ternary solubility data. This paper shows the same tendency as seen in this work, where the deviations for activity coefficient and osmotic coefficient increase slightly however not significantly when solubility is included in the parameter estimation. The Lin et al. model was also parameterized to apparent molar volume which also shows to increase slightly when solubility was included. For comparison the Lin et al. deviation for $\mathrm{NaCl}$ change from $1.43 \%$ to $1.56 \%$ for mean ionic activity coefficient and from $1.25 \%$ to $1.29 \%$ for osmotic 
coefficients. The deviations for $\mathrm{NaCl}$ at $298.15 \mathrm{~K}$ for this work is seen to change with the same magnitude, with osmotic coefficient going from $1.72 \%$ to $1.77 \%$, and the activity coefficient deviations changing from $2.21 \%$ to $2.43 \%$. In Lin et al. the deviation of osmotic coefficient for $\mathrm{Na}_{2} \mathrm{SO}_{4}$ changes from $0.43 \%$ to $3.06 \%$ when including solubility data, and in comparison for this work it changes from $0.71 \%$ to $0.92 \%$. A direct comparison between the deviations of the two different models are, however, difficult because the data used is not likely to be identical. Also if the model of this work was only parameterized at $298.15 \mathrm{~K}$ it is likely to lower the deviations at that temperature.

While eCPA in this implementation has been proven to match Extended UNIQUAC on average for the investigated properties, it is of interest to evaluate if improvements can be made to the model. The main challenge observed by the model is to represent both the solubility and the high molality / high temperature data. In this implementation several assumptions and decisions are made. The model does not account explicitly for ion-solvent association or ion-ion association. Including such interactions could improve the description but may add additional complexity and thus other solutions should be investigated prior to adding complexity to the model. In term of parameters, the use of salt specific interaction parameters is a limitation. Estimating instead ion-solvent interaction parameters will be a more complex parameterization, however, it will also provide the possibility to use the single ion energy parameter, $a_{0}$, as an additional adjustable parameter.

\section{Conclusion}

This work presents a new parameterization of the eCPA EoS with salt specific parameters. The focus is 
on accurate description of the solubility, and low deviation correlations are obtained for all salts investigated. Compared to parameters only determined from osmotic coefficients and activity coefficients (Maribo-Mogensen et al. ${ }^{17}$ ), the inclusion of the solubility data in the parameterization has not affected the deviations of the osmotic coefficients and activity coefficients significantly, with deviations changing from $4.0 \%$ to $4.6 \%$ for the osmotic coefficient and $6.8 \%$ to $7.9 \%$ for the mean ionic activity coefficient. While the average deviations were not affected much, the increase in deviations of the activity coefficients was almost entirely based on decreased accuracy at high temperature and high molality. The model is, furthermore, compared to the activity coefficient model, Extended UNIQUAC, showing that the eCPA has more accurate solubility description at higher temperatures compared to Extended UNIQUAC, but also that Extended UNIQUAC performs more uniform in its known valid temperature range. On average, the two models perform rather similar with regards to the properties examined in this work.

\section{Acknowledgements}

The authors gratefully acknowledge the CHIGP Industry consortium (Statoil, BP, Petrobras) and DTU for funding this work as part of the project "Development of the Electrolyte CPA Equation of State".

\section{Nomenclature}

$\begin{array}{cl}A & \text { Helmholtz energy } \\ a_{0} & \text { SRK energy parameter } \\ a_{i} & \text { Activity of component } i \\ a_{w} & \text { Activity of water } \\ b & \text { SRK co-volume parameter } \\ a_{i}, b_{i}, c_{i} & \text { Parameters of heat capacity correlation }\end{array}$




$\begin{array}{cl}c_{1} & \text { SRK energy parameter } \\ C_{p}^{0} & \text { Standard state heat capacity } \\ d & \text { Hard sphere diameter } \\ e & \text { Elementary charge } \\ g(\rho) & \text { Radial distribution function } \\ g & \text { Kirkwood g-factor } \\ g^{E, \infty} & \text { Excess gibbs energy } \\ \Delta G^{0} & \text { Standard state Gibbs energy of formation } \\ \Delta_{h y d} H & \text { Enthalpy of hydration } \\ \Delta H^{0} & \text { Standard state enthalpy of formation } \\ k_{B} & \text { Boltzmann's constant } \\ K & \text { Equilibrium constant } \\ n & \text { number of moles } \\ N_{A} & \text { Avogadro's number } \\ R & \text { Gas Constant } \\ R_{B o r n} & \text { Born radius } \\ T & \text { Temperature } \\ T_{r} & \text { Reduced Temperature } \\ T_{C} & \text { Critical Temperature } \\ T_{\alpha} & \text { Parameter in temperature dependence } \\ \Delta U & \text { Interaction energy parameter } \\ V & \text { Volume } \\ v & \text { Molar volume or stoichiometric number } \\ X_{A_{i}} & \text { Fraction of site A on component i that is not bound to any other site } \\ Z & \text { lonic valence } \\ Z & \text { Charge } \\ & \end{array}$

$\alpha \quad$ Non-Randomness parameter (HV/NRTL) or Parameter in temperature dependence

$\beta_{A_{i} B_{j}} \quad$ Association volume

$\gamma_{ \pm}^{m} \quad$ Mean lonic activity coefficient

$\Delta_{A_{i} B_{j}} \quad$ Association strength

$\varepsilon_{A_{i} B_{j}} \quad$ Association energy

$\varepsilon_{r} \quad$ Dielectric constant

$\varepsilon_{0} \quad$ Dielectric permittivity of vacuum

$\varepsilon_{\infty} \quad$ Infinite frequency permittivity

$\Phi \quad$ Osmotic coefficient

$\varphi \quad$ Fugacity

$\kappa \quad$ Inverse Debye screening length

$\mu \quad$ Dipole moment

$\rho \quad$ Density 


\section{Literature}

(1) Kontogeorgis, G. M.; Folas, G. K. Thermodynamic Models for Industrial Applications: From Classical and Advanced Mixing Rules to Association Theories; John Wiley \& Sons, 2009.

(2) García, A. V.; Thomsen, K.; Stenby, E. H. Prediction of Mineral Scale Formation in Geothermal and Oilfield Operations Using the Extended UNIQUAC Model. Geothermics 2005, 34 (1), 61.

(3) Snell, J. F. Three-Component System. J. Phys. Chem. 1898, 2, 457.

(4) Frankforter, G. Equilibria in the Systems, Water, Acetone and Inorganic Salts. J. Am. Chem. Soc. 1914, 36, 1103.

(5) Lynn, S. Recovery of Anhydrous Na2SO4 from SO2-Scrubbing Liquor by Extractive Crystallization: LiquidLiquid Equilibria for Aqueous Solutions of Sodium Carbonate, Sulfate, And/or Sulfite plus Acetone, 2-Propanol, or Tert-Butyl Alcohol. Ind. Eng. Chem. Res. 1996, 35 (11), 4236.

(6) Hendriks, E.; Kontogeorgis, G. M.; Dohrn, R.; de Hemptinne, J.-C.; Economou, I. G.; Žilnik, L. F.; Vesovic, V. Industrial Requirements for Thermodynamics and Transport Properties. Ind. Eng. Chem. Res. 2010, 49 (22), 11131.

(7) Chen, C.-C.; Britt, H. I.; Boston, J. F.; Evans, L. B. Local Composition Model for Excess Gibbs Energy of Electrolyte Systems. Part I: Single Solvent, Single Completely Dissociated Electrolyte Systems. AIChE J. 1982, 28 (4), 588.

(8) Thomsen, K. Aqueous Electrolyte Model Parameters and Process Simulation, Technical University of Denmark, 1997.

(9) Galindo, A.; Gil-Villegas, A.; Jackson, G.; Burgess, A. N. SAFT-VRE: Phase Behavior of Electrolyte Solutions with the Statistical Associating Fluid Theory for Potentials of Variable Range. J. Phys. Chem. B 1999, 103 (46), 10272.

(10) Cameretti, L. F.; Sadowski, G.; Mollerup, J. M. Modeling of Aqueous Electrolyte Solutions with PerturbedChain Statistical Associated Fluid Theory. Ind. Eng. Chem. Res. 2005, 44 (9), 3355.

(11) Held, C.; Cameretti, L. F.; Sadowski, G. Modeling Aqueous Electrolyte Solutions Part 1. Fully Dissociated Electrolytes. Fluid Phase Equilib. 2008, 270 (1-2), 87.

(12) Held, C.; Reschke, T.; Mohammad, S.; Luza, A.; Sadowski, G. ePC-SAFT Revised. Chem. Eng. Res. Des. 2014, $92(12), 1884$.

(13) Tan, S. P.; Ji, X.; Adidharma, H.; Radosz, M. Statistical Associating Fluid Theory Coupled with Restrictive Primitive Model Extended to Bivalent lons. SAFT2: 1. Single Salt + Water Solutions. J. Phys. Chem. B 2006, 110 (33), 16694.

(14) Courtial, X.; Ferrando, N.; de Hemptinne, J.-C.; Mougin, P. Electrolyte CPA Equation of State for Very High Temperature and Pressure Reservoir and Basin Applications. Geochim. Cosmochim. Acta 2014, 142.

(15) Ji, X.; Adidharma, H. Ion-Based SAFT2 to Represent Aqueous Single- and Multiple-Salt Solutions at 298.15 K. Ind. Eng. Chem. Res. 2006, 45 (22), 7719.

(16) Inchekel, R.; de Hemptinne, J.-C.; Fürst, W. The Simultaneous Representation of Dielectric Constant, Volume and Activity Coefficients Using an Electrolyte Equation of State. Fluid Phase Equilib. 2008, 271 (1-2), 
19.

(17) Maribo-Mogensen, B.; Thomsen, K.; Kontogeorgis, G. M. An Electrolyte CPA Equation of State for Mixed Solvent Electrolytes. AIChE J. 2015, 61 (9), 2933.

(18) Lin, Y.; Thomsen, K.; de Hemptinne, J. Multicomponent Equations of State for Electrolytes. AlChE J. 2007, $53(4), 989$.

(19) Jin, G.; Donohue, M. D. An Equation of State for Electrolyte Solutions. 3. Aqueous Solutions Containing Multiple Salts. Ind. Eng. Chem. Res. 1991, 30 (1), 240.

(20) Simon, H.-G.; Kistenmacher, H.; Prausnitz, J. M.; Vortmeyer, D. An Equation of State for Systems Containing Electrolytes and Nonelectrolytes. Chem. Eng. Process. Process Intensif. 1991, 29 (3), 139.

(21) Ji, X.; Tan, S. P.; Adidharma, H.; Radosz, M. Statistical Associating Fluid Theory Coupled with Restricted Primitive Model to Represent Aqueous Strong Electrolytes: Multiple-Salt Solutions. Ind. Eng. Chem. Res. 2005, 44 (19), 7584.

(22) Lee, B.-S.; Kim, K.-C. Modeling of Aqueous Electrolyte Solutions Based on Perturbed-Chain Statistical Associating Fluid Theory Incorporated with Primitive Mean Spherical Approximation. Korean J. Chem. Eng. 2010, 26 (6), 1733.

(23) Kontogeorgis, G. M.; Voutsas, E. C.; Yakoumis, I. V; Tassios, D. P. An Equation of State for Associating Fluids. Ind. Eng. Chem. Res. 1996, 35 (11), 4310.

(24) Hückel, E.; Debye, P. Zur Theorie Der Elektrolyte. I. Gefrierpunktserniedrigung Und Verwandte Erscheinungen. Phys. Zeitschrift 1923, 24, 185.

(25) Born, M. Volumen Und Hydratationswärme Der lonen. Zeitschrift für Phys. 1920, 1 (1), 45.

(26) Soave, G. Equilibrium Constants from a Modified Redlich-Kwong Equation of State. Chem. Eng. Sci. 1972, 27 (6).

(27) Chapman, W. G.; Gubbins, K. E.; Jackson, G.; Radosz, M. SAFT: Equation-of-State Solution Model for Associating Fluids. Fluid Phase Equilib. 1989, 52 (pt 1), 31.

(28) Wertheim, M. S. Fluids with Highly Directional Attractive Forces. I. Statistical Thermodynamics. J. Stat. Phys. 1984, 35 (1-2), 19.

(29) Wertheim, M. S. Fluids with Highly Directional Attractive Forces. II. Thermodynamic Perturbation Theory and Integral Equations. J. Stat. Phys. 1984, 35 (1-2), 35.

(30) Wertheim, M. S. Fluids with Highly Directional Attractive Forces. III. Multiple Attraction Sites. J. Stat. Phys. 1986, $42(3-4), 459$.

(31) Wertheim, M. S. Fluids with Highly Directional Attractive Forces. IV. Equilibrium Polymerization. J. Stat. Phys. 1986, 42 (3-4), 477.

(32) Michelsen, M. L.; Hendriks, E. M. Physical Properties from Association Models. Fluid Phase Equilib. 2001, 180, 165.

(33) Michelsen, M. L. Robust and Efficient Solution Procedures for Association Models. Ind. Eng. Chem. Res. 2006, 45 (25), 8449. 
(34) Kontogeorgis, G. M.; V. Yakoumis, I.; Meijer, H.; Hendriks, E.; Moorwood, T. Multicomponent Phase Equilibrium Calculations for Water-methanol-alkane Mixtures. Fluid Phase Equilib. 1999, 158-160 (111), 201.

(35) Thomsen, K.; Rasmussen, P.; Gani, R. Correlation and Prediction of Thermal Properties and Phase Behaviour for a Class of Aqueous Electrolyte Systems. Chem. Eng. Sci. 1996, 51 (14), 3675.

(36) Maribo-Mogensen, B.; Kontogeorgis, G. M.; Thomsen, K. Comparison of the Debye-Hückel and the Mean Spherical Approximation Theories for Electrolyte Solutions. Ind. Eng. Chem. Res. 2012, 51 (14), 5353.

(37) Maribo-Mogensen, B.; Kontogeorgis, G. M.; Thomsen, K. Modeling of Dielectric Properties of Complex Fluids with an Equation of State. J. Phys. Chem. B 2013, 117 (12), 3389.

(38) Marcus, Y. Electrostriction in Electrolyte Solutions. Chem. Rev. 2011, 111 (4), 2761.

(39) Wu, J. Phase Equilibria for Systems Containing Hydrocarbons, Water, and Salt: An Extended Peng-Robinson Equation of State. Ind. Eng. Chem. Res. 1998, 37 (5), 1634.

(40) Myers, J. A. An Equation of State for Electrolyte Solutions Covering Wide Ranges of Temperature, Pressure, and Composition. Ind. Eng. Chem. Res. 2002, 41 (13), 3282.

(41) Raatschen, W.; Harvey, A. H.; Prausnitz, J. M. Equation of State for Solutions of Electrolytes in Mixed Solvents. Fluid Phase Equilib. 1987, 38 (1-2), 19.

(42) Haghtalab, A.; Mazloumi, S. H. A Square-Well Equation of State for Aqueous Strong Electrolyte Solutions. Fluid Phase Equilib. 2009, 285 (1-2), 96.

(43) Haghtalab, A.; Mazloumi, S. H. Electrolyte Cubic Square-Well Equation of State for Computation of the Solubility CO 2 and H 2 S in Aqueous MDEA Solutions. Ind. Eng. Chem. Res. 2010, 49 (13), 6221.

(44) Rozmus, J.; de Hemptinne, J.-C.; Galindo, A.; Dufal, S.; Mougin, P. Modeling of Strong Electrolytes with ePPC-SAFT up to High Temperatures. Ind. Eng. Chem. Res. 2013, 52 (29), 9979.

(45) Zuber, A.; Checoni, R. F.; Mathew, R.; Santos, J. P. L.; Tavares, F. W.; Castier, M. Thermodynamic Properties of 1:1 Salt Aqueous Solutions with the Electrolattice Equation of State. Oil Gas Sci. Technol. - Rev. d'IFP Energies Nouv. 2013, 68 (2), 255.

(46) Zuber, A. Thermodynamic Properties of Aqueous Solutions of Single and Multiple Salts Using the QElectrolattice Equation of State. Fluid Phase Equilib. 2014, 362.

(47) Rashin, A. Reevaluation of the Born Model of Ion Hydration. J. Phys. Chem. 1985, 89 (26), 5588.

(48) Wagman, D.; Evans, W.; Parker, V.; Schumm, R.; Halow, I.; Bailey, S.; Churney, K.; Nuttal, R. The NBS Tables of Chemical Thermodynamic Properties - Selected Values for Inorganic and C-1 and C-2 Organic-Substances in SI Units. J. Phys. Chem. Ref. Data 1982, 11.

(49) Thomsen. CERE Electrolyte Database http://www.cere.dtu.dk/expertise/data-for-aqueous-salt-solutions.

(50) Tan, S. P.; Adidharma, H.; Radosz, M. Statistical Associating Fluid Theory Coupled with Restricted Primitive Model To Represent Aqueous Strong Electrolytes. Ind. Eng. Chem. Res. 2005, 44 (12), 4442. 
For Table of Contents Only

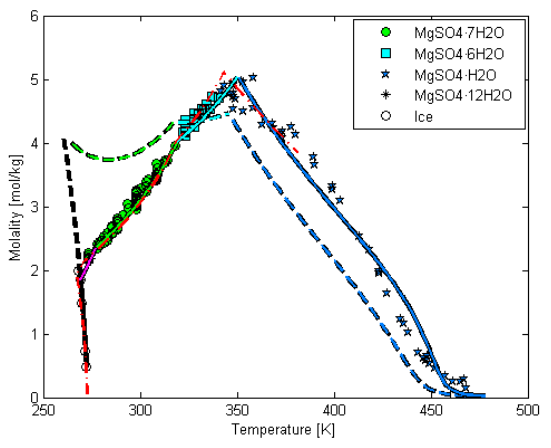

